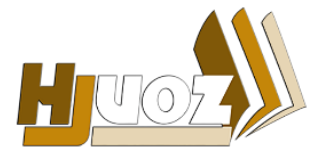

hjuoz.uoz.edu.krd p-ISSN: $2410-7557$

e-ISSN: $2518-5128$
كَّوارا زانستيّن مروّقايهتى يا زانكوّيا زاخوّ

مجلة العلوم الانسانية لجامعة زاخو

Humanities Journal of University of Zakho (HJUOZ) Vol. 5, No. 3, pp. 695-712, Sept.-2017

\title{
الشعور بالإغتراب النفسي وعلاقته بإستخدام الإنترنت لدى طلبة جامعة زاخو
}

\author{
زاهد سامي محمد و جيهان حسين عمر \\ قسم علم النفس، فاكولتي العلوم الانسانية، جامعة زاخو، اقليم كردستان - العراق. \\ https://doi.org/10.26436/2017.5.3.424 2017/09 2016/04 تاريخ الاستلاميخ القبول: تاريخ النشر:
}

الملخص:

هدف البحث الى التعرف على الشعور بالإغتراب النفسي وعلاقته بإستخدام الإنترنت لدى طلبة جامعة زاخو إعتمادا على متغير الجنس والمرحلة

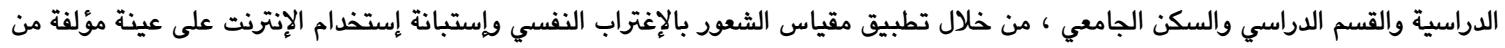

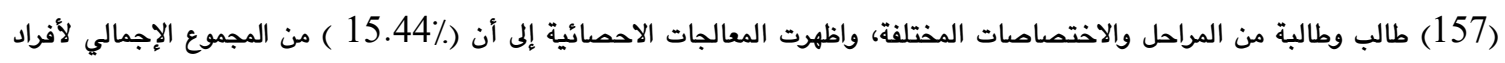

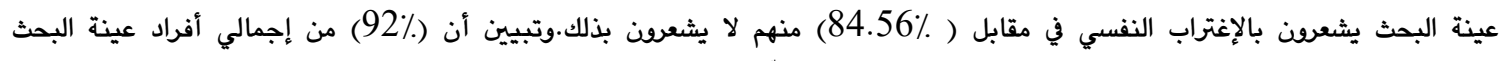

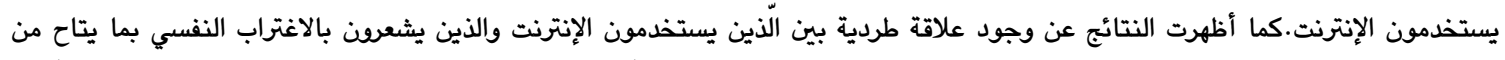

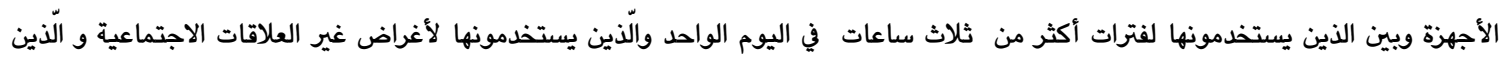

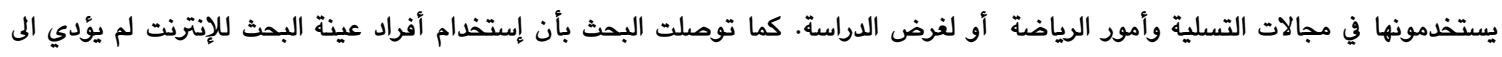

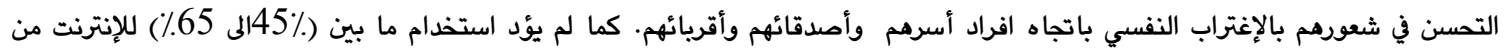

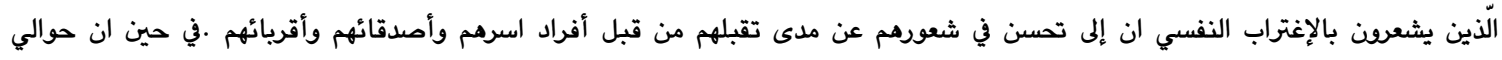

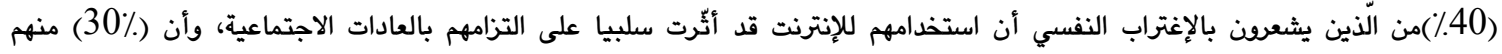

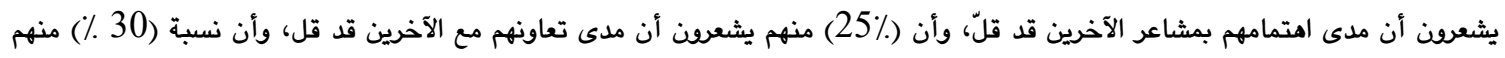
يشعرون ان أداء مسؤلياتهم الاجتماعية تجاه الآخرين قد قل .وأيضا أن حوالي(50\%) منهم يشعرون بأنهانه بعد استخدامهم للإنترنت قلل من

$$
\text { نشاطاتهم الاجتماعية في محيطهم الاجتماعي. }
$$

الكلمات الدالة: الشعور، الإغتراب النفسي، الإنترنيت، الطلبة، جامعة زاخو.

ملاحظة الطلبة اليومية من إثناء عملهم كتدريسين في الجامعة ضعف دألتات

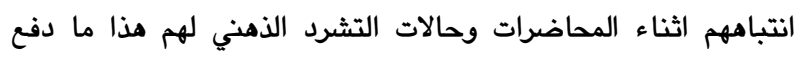

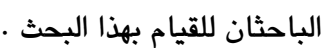

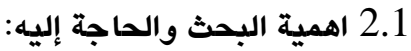
الإنسان كائن معقد يتشكل من جانبين أساسيين وهم الجانب الجاني

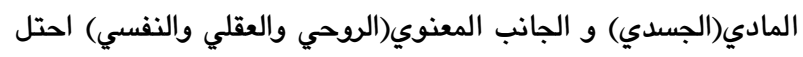

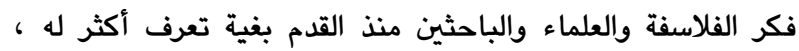
وتعرّف آلية تكوين وتطور المشاعر والتفكير والإنفعالات. وكيفية

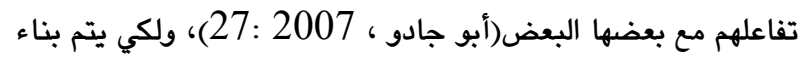
شخصية متكاملة يشارك الحياة الإجتماعية مع الآخرين ويقبل بالواقع

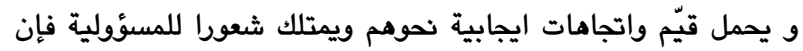
له مطاليب مادية ونفسية وإجتماعية ينبغي أن يحقيقها(زهران،

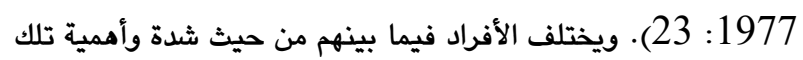
الحاجات ضمن المراحل العمرية التي يمر بها، ولاينمي الفرد شخصية

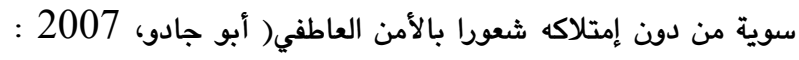

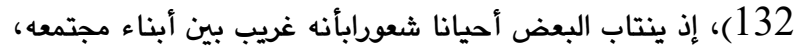
فيعيش مغتربا عن نفسه وذلك حين تنفصم عرى الوثاق بينه وبين

\section{1. التعريف بالبحث}

1.1

تعد ظاهرة الإغتراب النفسي ظاهرة نفسية اجتماعية ومشكلة إنسانية

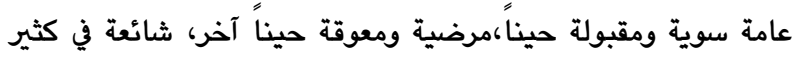
من المجتمعات بغض النظر عن النظم والإيديولوجيات والمستوى الاقتصادي والتقدم المادي والتكنولوجيا، كما أنها تعتبر معاناة للإنسان المعاصر وإن تعددت مصادرها وأسبابها، وإذا كانت دراسة الإنها

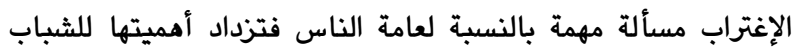

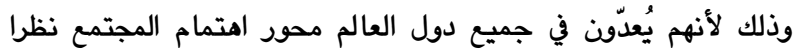
للدود الذي يمكن للشباب القيام به في زيادة الإنتاج والإسهام في بناء الدول والمجتمعات، لأنهم هم مصدر الطاقة المادية والمعنوية الحقيقية

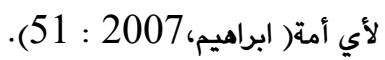
وقد وجد الباحثان بأن إقبال طلبة الجامعة لتقنية الإنترنت أصبحت ظاهرة نفسية واجتماعية ،ويشعر الباحثان أن هذه الدراسات لم تحظ

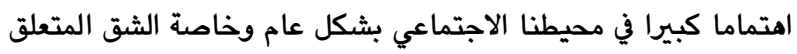

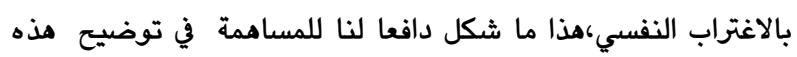
الظاهرة، كما ولدت فكرة إجراء هذه الدراسة للباحثين من خلال 
يسعى الإنسان باستمرار إلى خفض التوتر والتوصل إلى حالة اللإتزان النفسي من خلال عمليتي التمثل والموائمة فينشأ من جراء ذلك عملية التوافق النفسي والمعرفي والإجتماعي، يحاول أن يستفيد من ما يتوفر في بيئته لتنمية قدراته ومهاراته الحياتية بشكل عام(أبو جادو، 2007 : 157 - 158)، و لعل انتشار تقنية الإنترنت وتداخلها مع بعاه

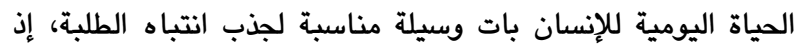
عمل أكثر من أي وسيلة أخرى على إحداث تغيرات سريعة وجذرية مست حياة الناس الاقتصادية والإجتماعية والنفسية والسياسية والتربوية والصحية والعلمية وغيرما. حيث ظهر أساليب جديدة للعمل والتجارة والدراسة وتشكيل أنماط جديدة للعلاقات بين الناس من هذا جانب، ومن جانب آخر أوجدت أعراضاً لحالات مرضية نفسية وجسدية و فساداً إدارياً واخلاقياً وقانونياً عند بعض المستخدمين في اهري أوساط اجتماعية مختلفة (محمد،2009 :4). وازداد اهتمام الباحثين خلال النصف الثاني من قرن العشرين بدراسة الشعور بالاغتراب النفسي كظاهرة انتشرت بين الافراد في المجتمعات المختلفة) عبدالهادي، مطر، 2005: 13). و يحاول الباحثان هنا تسليط الضوء على بعض جوانب مشاعر الطلبة ورغباتهم لكونهم يمرون بمرحلة انتقالية في حياتهم الاجتماعية وعن علاقة تلك المشاعر باستخدام تقنية الإنترنت. 1.2.1 وتبرز اهمية البحث الحالي من خلال: 1- أهمية حالة الشعور بالإغتراب النفسي لتأثيراتها على صحة الفرد ونشاطه وتبعاتها الإجتماعية والاقتصادية.

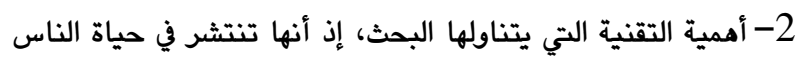
سريعا نتيجة للإقبال المتزايد عليها من قبل جميع شرائح المجتمع ويشكل خاص فئة طلبة الجامعة، فأنها تعمل على إثباع حاجاتهم النفسية والاجتماعية وتحقيق طموحاتهم المستقبلية، إضافة إلى انها تقدم خدمات مميزة للمستخدمين، كما إن استخدامها قد لاتخلو من تأثيرات سلبية عليهم مما يتطلب دراسة ذلك والعمل على تجنب الشباب من سلبياتها

3- أهمية الفئة التي يدرسها البحث ، لأنهم يعدون عناصر هامة لأية أمة الذي يكفل رفعتها و نهضتها و تقدمها.

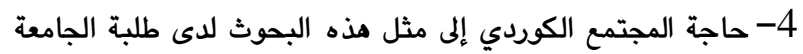
باعتبارهم قادة المستقبل.

3.1

يهدف الباحثان في البحث الحالي التعرّف على ما يلي : 1. مستوى الشعور بالاغتراب النفسي لدى أفراد العينة ككل.

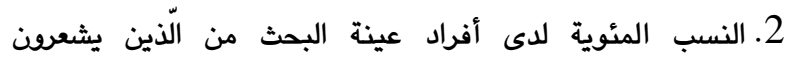
بالإغتراب النفسي من عدمه. 3. الفرقق بين أفراد عينة البحث ككل على مقياس الشعور بالإغتراب النفسي تبعا لمتغير الجنس والقسم الدراسي والسكن الجامعي.
نفسه(ياسين، 1992 : 9- 26)،ويشعرون بأن هناك شيئا ناقصا غير متحقق في علاقة ما- علاقة المرء بالآخرين ، بالمجتمع، أو حتى مع نفسه، فيجعله في أغلب الأحيان واهنا ضعيف الإرادة تضمحل عنده الشعور بالمسؤولية فلا يعدون إعدادا طيبا للإنخراط في الحياة الإجتماعية فيكونون نزير العطاء وقد يفقدون إحترامهم لذاتهم فيقعون في مزالق الأزمات النفسية .(مسن، كونجر، كاجان، 1986:

ويحاول الشباب في أي أمة التوجه نحو المعاصرة والحداثة، لذا باتوا Bruce , يصيبون بهوس الإقبال على هذه التقنية،وقد وجد بروس المهيك 1995) أن إستخدام الإنترنت قد أدى إلى زيادة التعاون بين الأكاديميين في استراليا مثلا و سهل عملية الإثراف على أبحاث الطلبة خارج استراليا، كما تبين دود هذه التقنية في دعم بناء المعرفة النشطة داخل الصف و كيف أن التواصل عبر الإنترنت يخلق فرص قراءة وكتابة واقعية و ذات معنى ( ربيع، 2006 : 203 - 204).

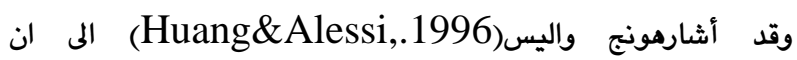
الانترنت يعتبر أحد أهم الوسائل التي يمكن ان تؤثر في حياة الناس اليومية، فالإنترنت كتلة من المعلومات تنمو، بحيث أصبحت مصدر قوة لحياة كثير من الافراد حول العالم وقد تنوعت استعمالاتها لدرجة انها وصلت مختلف مظاهر حياتنا الاجتماعية والاقتصادية والتربوية (الخطيب،2011 :721).فقد أدت التطورات الحاصلة في ميدان التكنولوجيا الى خلق العديد من المخاوف واثارة الجدل حول مخاطرها النفسية والاجتماعية والثقافية الناتجة من مضامين هذه التكنولوجيا والتي قد تكون لها تاثير سلبي على نفسية الفرد وقيمه وعاداته

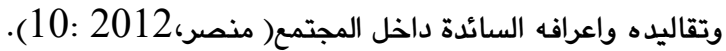
ويتأثر المناخ النفسي للفرد و خاصة الطلبة بالتغيرات الحاصلة في

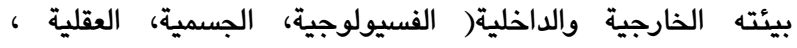
الإجتماعية)، فإذا كان الإنتقال سريعا ومتعدد الجوانب ينبغي أن يكون التكيّف موازيا لها (دسوقي، :269 - 273 )، وإن الكثير من معاناة الطلبة في مرحلة المراهقة المتأخرة تاتي من إخفاق البعض في مواكبة التغير بسبب النموغير المتناسق لشكل الجسم عند البعض والخصائص الجنسية الأولية والثانوية وخصائص النمو الإنفعالي التي تتسم بالتذبذب مع سطحية العواطف بين الحب والكره وبين الفرح والحزن والجبن والشجاعة والتدين والإلحاد وخصائص نمو القدرات

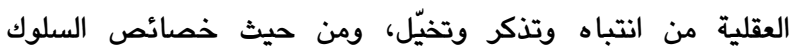
الإجتماعي تظهر ذلك جليا في التحول من الإعتماد على الغير إلى ولى الأستقلال الذاتي والإحساس بالهوية وتكوين قيم ذاتية نابعة من خبراته الشخصية الضيقة والتي ينعكس بشكل واضح في كيفية

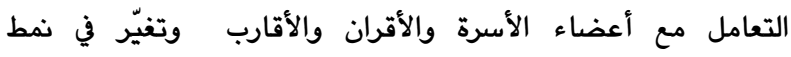
العلاقة(الزعبي ، 2001 ، 420- 421). 
لتشكيل شبكة واحدة ضخمة تنقل المعلومات من منطقة لأخرى ويسرعة فائقة ، ويشكل دائم التطور" (الحيلة ، 1998 :376).

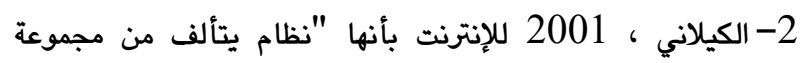
ضخمة من أجهزة الكومبيوتر المتصلة فيما بينها بواسطة بروتوكول

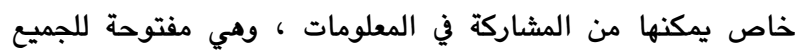
ضمن آلية معينة وهذه الكومبيوترات موجودة في مواقع مختلفة من

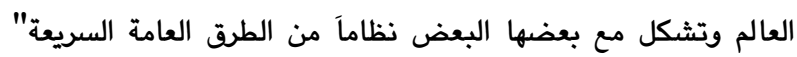
(محمد، (15:2009)

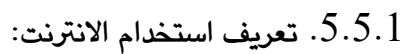
تعريف الاسطل، 2011" هو الجلوس امام شبكة الانترنت بتجاوذ حدود الزمان والمكان ومشاغل الحياة مؤديا هذا الاستخدام لخلل وظيفي في العمليات النفسية والمعرفية ،وعلاقته مع ذاته ومع الاخديان هذان الاسفين. (الاسطل ، 5: 2011) 6.5.1. التعريف الاجرائي لاستخدام الإنترنت : (دال

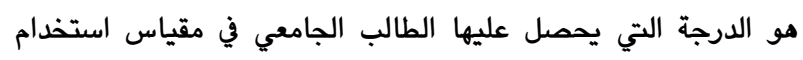

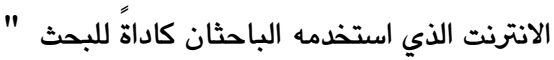

\section{2. خلفية نظرية ودراسات سابقة}

يتضمن هذا الفصل عرضا لما ورد في الأدبيات تخص الشعور بالاغتراب النفسي واستخدام الانترنت ، ومن ثم عرض لبعض دراسات

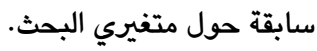

$$
1.2 \text { الشعور بالاغتراب النفسي: }
$$

1.1.2 لمحة عن الشعور الاغتراب النفسي: لقد استخدمت كلمة

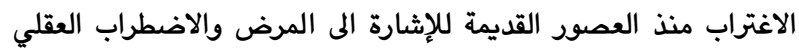
mental disorder

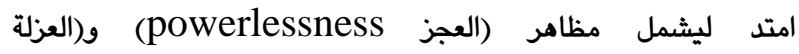
(isoliation (withdrwal (rejecation والاغتراب مصطلح شديد العمق وعريق الاصل ،ضارب الجذور الى فجر البشرية جمعاء اذ يعود الى تلك اللحظة المتعالية التي غربت فيها

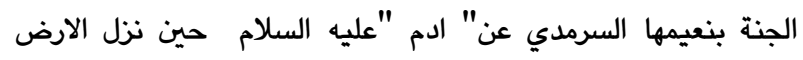

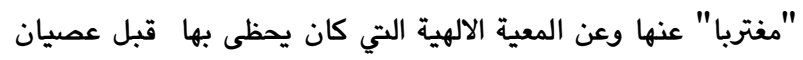
امر ربه فتلك هي بحق وصدق اولى مشاعر الاغتراب( خليفة ،2003

كان لإريك فروم شأن كبير في تعميم مصطلح الاغتراب، ولقد اختار مفهوم الاغتراب باعتباره النقطة التي انطلق منها لتحليل الشخصية فئرية الاجتماعية المعاصرة.(عباس،2008 : (1962,fromm)

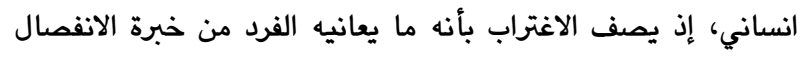

4. نسبة استخدام الانترنت وعلاقته بالإغتراب النفسي لدى أفراد

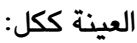
5. الفروق بين أفراد عينة البحث من الذين يشعرن بالإغتراب النفي تبعا لمتغي::(الجنس-القسم الدراسي-المرحلة الدراسيةالسكن الجامعي-استخدام الإنترنت).

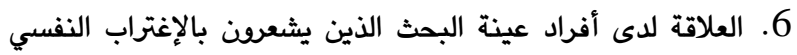

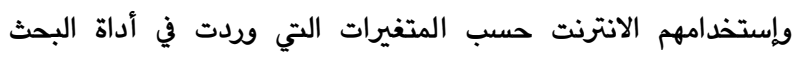
ل الإستخدام الإنترنت 4.1 يتحدد البحث الحالي بطلبة جامعة زاخو للمرحلتين (الأولى والرابعة)

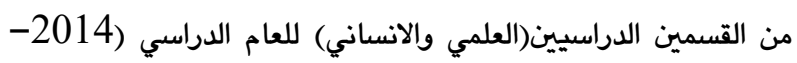
5.1 2015 تصديد المصطلحات

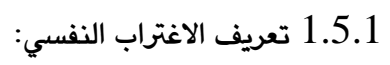

1- جورارد ولاندزمن، 1988 "الاغتراب يعني الكبت،وما دام المرء

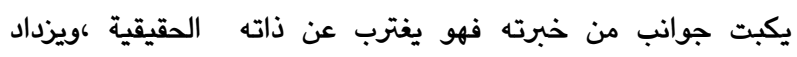
الاغتراب النفسي بزيادة الكبت و عن طريقه يحاول ان يقنع نفسه بانه شخص اخر(جورارد ولاندزمن ، 1988: 235). 2- اريك فروم،1963" الاغتراب عبارة ابتعاد الفرد عن نفسه باستسلامه لقيم المجتمع السائد خاصة في المجتمعات الصناعية الديثة التي تقوم على مبدأ الفردية و الاستهلاكية ويعرض ارادة الفرد

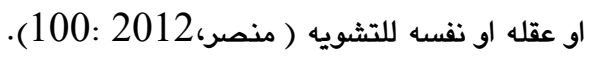

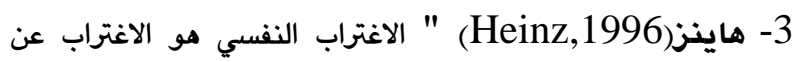

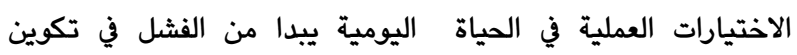
الهوية،ويرتبط بخبرات التعلم لدى الشباب، و بخيارات المستقبل في الحياة و الامتيازات الاجتماعية و كذلك ترتبط بنمو الميول (صالح،2008: 107) 4- تعريف زهران،2002 " بانه شعود الفرد بعدم الانتماء و

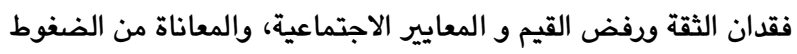
النفسية،وتعرض وحدة الشخصية للضعف و الانهيار بتاثر العمليات

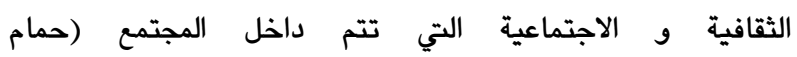
(73: 2.5.1 التعريف النظري للأغتراب يعرف الباحثان الاغتراب النفسي " بانه شعورالفرد بالوحدة وضعف للاغراب الانتماء للجماعة وانفصال الفرد عن ذاته وعن الاخرين" لإنهاب

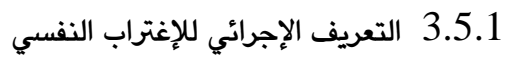

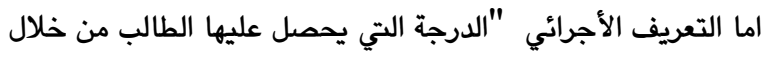

الاستجابة على مقياس الاغتراب النفسي المعد من قبل الباحثان" 4.5.1 ت تعرف الانترنت 1-الحيلة ، 1998 للإنترنت على أنها "عبارة عن كل الشبكات الحاسوبية المحلية التي يتصل بعضها ببعض في جميع انحاء العالم 
2.2. النظريات المفسرة للاغتراب النفسي هناك العديد من النظريات التي فسرت الاغتراب النفسي وفقاً لمنهجها العلمي والفلسفي وسوف يتناول الباحثان أهم هذه النظريات وكما وقد اشار عبد المختار (1998) علاقة الاغتراب بالوجود الانساني واستيظلين 1.2 .2 نظرية التحليل النفسي للاغتراب: يرى( فرويد)، بأن الأغتراب هو الأثر الناتج عن الحضارة من حيث أن الحضارة التي أوجدها الفرد جاءت متعاكسة ومتعارضة مع تحقيق أهدافه ورغباته وما يصبو اليه. فالأغتراب ينشأ نتيجة الصراع بين الذات وضوابط المدنية أو الحضارة حيث تتولد عند الفرد مشاعر القلق والضيق عند مواجهه الضغوط الحضارية بما تحمل من تعاليم وتعقيدات مختلفة وهذا بالتالي يدفع الفرد الى اللجؤ الى الكبت كآلية دفاعية تلجأ اليها (الآنا) كحل للصراع الناشئ بين رغبات الفرد وأحلامه وبين تقاليد المجتمع وضوابطه، ومن الطبيعي أن يكون هذا حلا واهنا تلجأ اليه (لائ الآنا) مما قد يؤدي بالتالي الى مزيد من الشعور بالقلق والأغتراب. لذا فأن(فرويد) يعتقد بأن الحضارة قامت على حساب مبدأ اللذة ولم تقدم للأنسان سوى الأغتراب.( الساعدي، 2007 : 21 فيديان وترجع "موني "اسباب الاغتراب لدى الانسان الى ضغوط داخلية ،حيث يوجه معظم نشاطه نحو الوصول الى اعلى درجات الكمال حتى

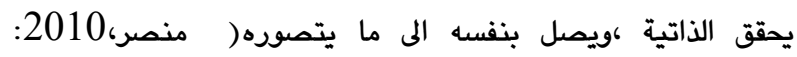

2.2.2 النظرية السلوكية والأغتراب: يرى أصحاب هذه النظريه بأن المشكلات السلوكية هي عبارة عن أنماط من الاستجابات الخاطئة أو غير السوية المتعلمة بارتباطاتها بمثيرات منفردة ويحتفظ بها الفرد لفاعليتها في تجنب مواقف أو خبرات غير مرغوية. وأن الفرد وفقا لهذه النظرية ( يشعر بالأغتراب عن ذاته عندما ينصاع ويندمج بين الأخرين بلا رأي أو فكر محدد حتى لا يفقد التواصل معهم ويدلا من

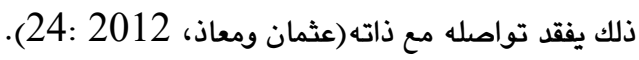
3.2 .2 الاغتراب بنظر أصحاب المذهب الإنساني: نظر ماسلو للاغتراب من خلال ما اطلق عليه تزييف الوعي نتيجة انفصال الانسان عن ذاته وعن تراثه الداخلي وهذا التزييف يجعل الفرد يفقد شعوره بهويته ومن ثم تظهر عليه اثار الاضطرابات النفسية التي تتمثل في الشعور بالقلق و الياس ،وتطور مشاعر الذنب واللاهدف ويمضي الانسان حياته من خلال الخوف ويفقد الانسان عندها القدرة على الاستمتاع بالحياة (العقيلي،2004: 14) من حلان

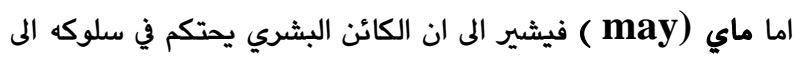
قيم يتمثلها ويفسر حياته وعالمه في ضوء بعض الرموز والمعاني وان هذه القيم تسبب له القلق والتوتر فالقلق من التهيب يستثيره تهديد القيم التي يتمثلها الفرد كغاية الغايات والتي بدونها يعاني الاغتراب ويفتقد الاحساس بوجوده كانسان ( كريمة 2012 :34). 4.2 .2 نظرية المجال والاغتراب
عن وجوده الإنساني وعن مجتمعه وعن الافعال التي تصدر عنه فيفقد سيطرته عليها ويصبح متحكم فيه فلا يشعر بأنه مركز لعالمه ومتحكم في تصرفاته (حمام والهويش، 2010: 17). النقاط التالية 1- ان الوجود الانساني وجود مغترب بالضرورة الالهية ،فاغتراب ادم عليه السلام من الجنة ونزوله للأرض ،وكذلك ميلاد كل طفل من رحم الام يعتبر بمثابة البذرة الاولى للاغتراب. 2- ان الوجود نقيض الاغتراب. 3- ان الاغتراب مفهوم يضرب جذوره في اعماق الفلسفة ، فهيجل "ابو الوجتراب

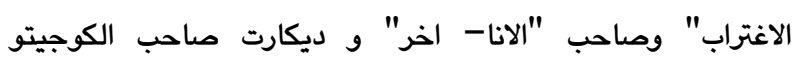

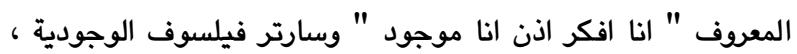
ونيتشه يرى ان الموجود خارج نفسه ( خليفة ،2003 :20). 2.1 .2

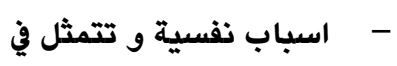

أ- الصراعبين الدوافع والرغبات المتعارضة و بين الحاجات التي لا ولا يمكن اشباعها في وقت واحد مما يؤدي الى التوتر الانفعالي والقلق واضطراب الشخصية . ب-الإحباطات التي يعاق الرغبات الاساسية او الحوافز او المصالح الخاصة بالفرد، ويرتبط الاحباط بالشعور بالفشل والعجز التام والشعور بالقهر وتحقير الذات. ت- الحرمان التي تقلل الفرص لتحقيق دوافع او اشباع حاجات كما في حالة حرمان من الرعاية الوالدية و الاجتماعية. ( منصر،2012 (104: - اسباب اجتماعية: ومن اهمها ما يلي

أ- ضغوط البيئة الاجتماعية والفشل في مواجهة هذه الضغوط. ب- الثقافة المريضة التي تسود فيها عوامل الهدم والتعقيد . ت- التطور الحضاري السريع وعدم توافر القدرة النفسية على التوافق ث-اضطراب التنشئة الاجتماعية حيث تسود الاضطرابات في الاسرة

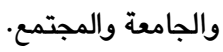
ج- تدهور نظام القيم وتصارعها بين الاجيال. ح- الضلال والبعد عن الدين والضعف الاخلاقي وتفشي الرزيلة. (عثمان ومعاذ، 20: 2012 (عن)

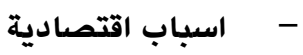
يعد ظهور عددا كبيرا من الافراد ذوي الدخل المرتفع وذوي الدخل المنخفض سببا كبيرا يترتب عليه اختلاف في مستوى المعيشة والحياة والمظهر.ويترتب على ذلك فقدان المعايير والقوة والوسائل التي يمكن بها زيادة السيطرة على الطبيعة مما يؤدي الى غياب اصحاب الدخل المحدود في نفس المجتمع( منصر، 2012 :105). 
بينه وبين الطباعة والتلفزيون، وهما الوسيلتان التكنولوجيتان

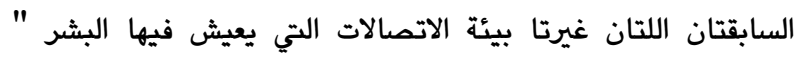

وأصبح شبابنا في العصر الحالي متعلقين جدا بالقنوات الفضائية ومواقع الانترنت وذلك لما تقدمه له من برامج ،كما انه اصبح يقلد كل بل ما يشاهده عبر هذه الوسائل من سلوكيات وعادات سواء اكانت مفيدة او مضرة بالنسبة له وذلك تحت شعار الموضة والتفتح على الاخر ومواكبة تطورات العصر ،حيث جعلت هذه التكنولوجيا واستخدام الانترنت الشاب الجامعي يعيش في عالم لا يدرك ماذا يفعل فيه، اذ جعلته يعيش في عالم خيالي بعيدا عن اسرته ومجتمعه ،ويفكر دوما في محاولة الوصول الى هذا العالم المثالي الذي صورته له استخدام الانترنت والتكنولوجيا في مخيلته، مما ولد لدى شبابنا مرض الاغتراب، الاحباط واليأس من واقعه المعاش مما جعله ينعزل عن مجتمعه محاولا خلق مجتمع موازي له يتميز بالافتراضية واللاواقعية يحدد فيه الفرد قوانينه ومعاييره على اسس نفعية لا تخرج عن دائرة الملذات التي لا تحترم حق الآخر) عبد الحي، 2008: 11

1.3.2 مشاكل استخدام للإنترنت: إن استغلال هذه التقنية لغايات سلبية،أدى إلى ظهور مجموعة من المشاكل في مجالات عدة

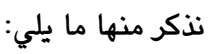
1- مشاكل اجتماعية: الاستخدام السلبي للإنترنت ساهمت في ظهور مشكلات اجتماعية متنوعة بين مستخدميها، إذ تشير بعض ف الدراسات إلى أنها تسبب في إضعاف العلاقات الاجتماعية بين أفراد الأسرة الواحدة والأقارب فكثرة استخدامها تؤدي إلى عدم اهتمام المستخدم بمسؤولياته الاجتماعية نحو ذويه وإممال واجباته الحياتية. (عبدالحميد 2002 : 22 ) 2- مشاكل نفسية لمستخدمي الإنترنت: تعد تقنية الإنترنت من أكثر وسائل الاتصال جاذبية بين مستخدميها التي تعمل على زيادة استقطاب جمهوره يوما بعد يوم ،وتتضاعف عدد مستخدميه سنة بعد أخرى، فهي تحتوي على أنواع من المثيرات البصرية والسمعية لمختلف المواضيع والأعمال الثقافية والعلمية مما دفع ببعض في المجال النفسي إلى دراسة تأثيراتها الإيجابية والسلبية على مستخدميه من مختلف الأعمار والبيئات الثقافية والإقتصادية. ورغم الإيجابيات الكثيرة قد تبين أن هناك أحيانا آثار سلبية للإنترنت على نفسية مستخدميه إذا لم يحسنوا التصرف فيه ، ويهذا الخصوص قد اثارت دراسة(Chih ,\& et ,al ,2003) بأن قضاء فترات طويلة باللهو واللعب على الإنترنت من العوامل التي تنذر للإصابة بالإدمان بالإنترنت وهذا النوع من الإدمان يكون إدمانا سلوكيا ويحدث ذلك عندما. يتعرض الشخص للإنترنت ويستخدمه بافراط وغالبا ما يظهرعليه
رائد هذه النظرية" ليفين" ان فحوى هذه النظرية يمكن أن ينصب في أنه عند التصدي للاضطرابات والمشكلات النفسية فأنها توجه الاهتمام بشكل مركز على شخصية العميل وخصائص هذه الشخصية المرتبطة بالاضطراب والمسببة له، وكذلك على خصائص الحيز الحياتي الخاص بالعميل في زمن حدوث الاضطراب بالإضافة الى

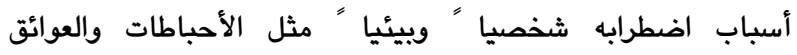
المادية.ويرى زهران" بأن الحواجز النفسية التي تحول دون تحقيق أهداف الفرد والصراعات وما قد يصحبها من أقدام ومجوم غاضب أو أحجام وتقهقر خائف وعلى هذا فأن الأغتراب منا ليس ناتجا" من عوامل داخلية فقط بل من عوامل خارجية تتضمن سرعة التغيرات البيئية والأتجاه نحو هذه التغيرات والعوامل.(الساعدي ،2007:

5.2 .2 تفسير نظرية السمات والعوامل للاغتراب النفسي: يعد ريموند كاتل من اهم رواد هذه النظرية وتركز هذه النظرية على العوامل المحددة التي تفسر السلوك البشرى و التى تمكن من تحديد سمات الشخصية 0 و تشير الدراسات التى تتناول سمات شخصية مرتفعى الاغتراب انهم بعدد من السمات منها التمركز حول

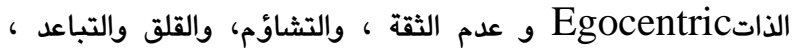
والوحدة النفسية ، وتوترات الحياة اليومية ، والشعور بفقدان القدرة على التحكم ، والاضطرابات في هوية الفرد ، و نقص العلاقات الصادقة مع اللاخرين ، وعدم القدرة على تبنى القيم المرغوية ، وعدم القدرة على التوحد مع الابوين ، وعدم القدرة على ايجاد تواصل بين الماضى و المستقبل ، وعدم الانسجام بين الفرد والاجيال السابقة.

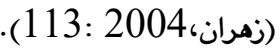
3.2 استخدام الانترنت: ان العالم اليوم يمر بحقبة جديدة في تطور سبل ايصال المعلومات فتقنيات الاتصالات تنفجر يوما بعد يوم.ولا يمكن التنبؤ لعالم. الاتصالات في المستقبل ،ذلك لان الاثياء التي تحصل عادة اكبر مما نتوقعه،وتعتبر الانترنت احدى التقنيات التي يمكن استخدامه بصفة عامة. (الخطيب، 11 (3: 201 : ويبدو أن عملية استخدام الإنترنت في مختلف أنحاء العالم في حالة تزايد مستمر(محمد، 2009: 7 8)، وتأتي أهمية استخدام الإنترنت إلى الخدمات التي تؤديها بكافة أنواعها وأشكالها إلى مستخدميه بأقل كلفة وجهد (محسن، 2005: 14) ومما يزيد من امميتها كونها تنقل المعلومة سريعاً بين وسطين بواسطة الأثير الالكتوني أو خطوط الهواتف. وقد أكد (جون نوتون ، د.ت) في كتابه تأريخ موجز للمستقبل : أصول الإنترنت ، قائلا : "الإنترنت واحد من أبرز الأشياء التي صنعها البشر طوال حياتهم ، وفيما يتعلق بتأثيره في المجتمع ، فانه يقف في صف واحد مع الطباعة والسكك الحديدية والتلغراف والسيارة والطاقة الكهريائية والتلفزيون، وريما يساوي بعض الناس 
احصائية، وقد بلغت عينة الدراسة(299) من الصفوف الثالثة والرابعة في الجامعة المستنصرية،وتوصلت الدراسة الى أن هناك فروق ذات دلالة أحصائية لصالح الذكور بانهم أكثر فهماً لذواتهم من الآناث. أما في مقياس الاغتراب فقد تبين عدم وجود فروق ذات دلالة احصائية بين الذكور والاناث، الآنه لوحظ وجود نزعة لدى الاناث الى الإغتراب

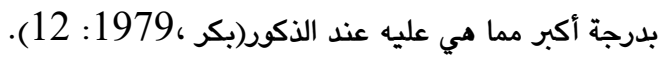
- الحديدي(1990): أجرى دراسة ميدانية حول مظاهر الآغتراب وعوامله لدى طلبة الجامعة الآردنية، حيث أعد الباحث آستبيان من جزئين أحدمما لقياس النسق الأجتماعي والثاني لقياس النسق التعليمي وتكون كل جزء من ستة أبعاد تمثل مظاهر الآغتراب وهي( فقدان المعايي،، الإنعزال الآجتماعي، فقدان السيطرة، اللامبالاة، عدم الآنتماء وفقدان المعنى.وتكونت عينة الدراسة من( 275) طالباً وطالبة أختيرت عشوائياً وأسفرت النتائج عن أنتشار ظاهرة الإغتراب بدرجة ضعيفة لدى(1.8\%) من أفراد العينة، ومتوسطة بنسبة

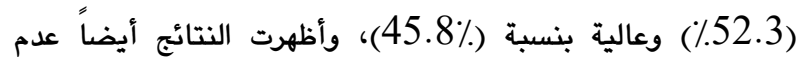
وجود فروق دالة أحصائياً في الاغتراب بالنسبة للجنس مع وجود فروق وائ دالة أحصائياً لانتشار ظاهرة الاغتراب بالنسبة لمتغير المستوى الدراسي وذلك لصالح طلبة السنة الدراسية الأولى، وأن طلبة الكليات العلمية يعانون من الاغتراب أكثر من طلبة الكليات الانسانية سواء في

$$
\text { النسق الآجتماعي والتعليمي..(الحديدي، } 1990 \text { :6). }
$$
- (متوالي، 1990): من أهداف دراسته التعرف على العلاقة بين

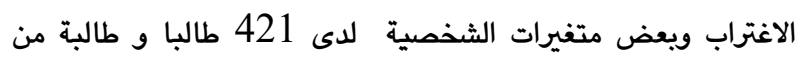
شباب جامعة دمياط ،حيث شملت المتغيرات الشخصية ،الانقباض والهستيريا والسايكوياث و الفصام و الانطواء الاجتماعي ،بموجب

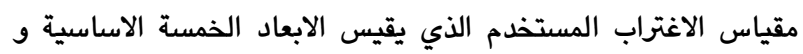
هي العزلة الاجتماعية واللامعيارية والعجز واللامعنى والعزلة الذاتية وقد بينت النتائج بأن شباب الجامعة يعانون من الشعور بالاغتراب

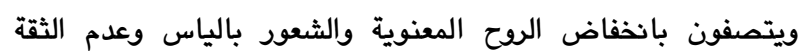
بالنفس وميل الى القلق والانطواء (صالح،2008: 115-116). - خليل (2002): بعنوان ( الاغتراب وعلاقته بالصحة النفسية لدى ومي طلبة الجامعات الفلسطينية في محافظة غزة) استهدف التعرف على الفروق في درجة الاغتراب لدى افراد عينة الدراسة التي تعزى لعدد من المتغيرات و هي ( الجنس -مكان الاقامة- نوع الكلية - المستوى التعليمي - المواطنة -نوع التعليم- والانتماء السياسي) وكذلك هدفت لمعرفة الفروق في درجة الصحة النفسية التي تعزى لعدد من المتغيرات السابقة ،ومعرفة العلاقة بين درجة الاغتراب ودرجة كل بعد

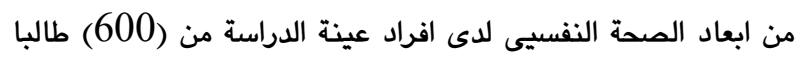
وطالبة واستخدم الباحث مقياس الاغتراب ومقياس الصحة النفسية

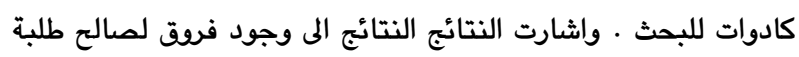
الجامعة على مقياس الاغتراب . ووجود فروق لصالح طلبة الكليات
أعراض القلق والإكتئاب وعدم القدرة على المواجهة الاجتماعية ، وتقل لديه مهارات التواصل الاجتماعي السليم (محمد، 2009 : 30) 2.3.2 نظريات التي فسرت استخدام الاتترنت: من النظريات التي فسرت استخدام الانترنت هي

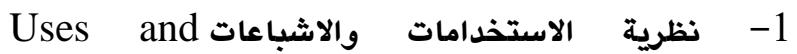
:Gratifications Theory جلبت هذه النظرية إهتمام الكثير من الباحثين الذين أرادوا التعرف

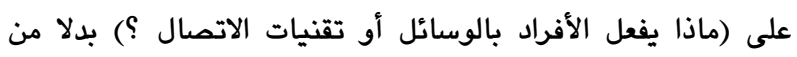
(ماذا تفعل الوسائل بالأفراد؟) ، وفيما يلي خمسة افتراضات ركز عليها أنصار هذا الاتجاه وهي الآتي :

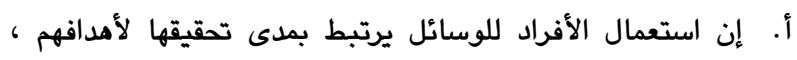
وهو نفي لاستعمالاتهم العفوية. ب. ترجع المبادرة للمستعمل في ربط إرضاء إحدى حاجاته بإختياره للوسيلة وإلغاء مفهوم ماذا تفعل الوسائل بالأفراد؟. ج. وجود علاقة تنافسية بين وسائل الاتصال ومصادر أخرى مفاء للحصول على رضا المستخدم . د. قدرة الأفراد على تشخيص دوافعهم ويالطرق المناسبة. هـ إن أحكام القيمة حول المعنى الثقافي لتقنيات الاتصال غير دقيقة إذا لم تسبق استكشاف اتجاهات المستخدمين التي تعتبر هي الأصل.( دليو ، 2003 : 2003 - 31).

2- نظرية الحاجات النفسية والاتصال Psycho needs and communications Theory تعد الحاجات النفسية من المحددات الهامة لعملية الاتصال ،ويتم اثباعها عن طريق التفاعل مع الآخرين ، وقد يكون الاثباع كاملا أو من لهات

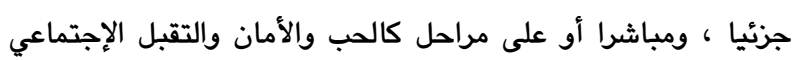
والشعور بالقدرة على الانجاز،وعندما يتعرض الفرد لمواقف مخيفة أو غامضة أو خارج عن سيطرته فانه يحاول أن يتقرب من أشخاص يفهمونه و يدعمونه ويعملون على خفض ذلك التوتر(الحلبي ، 2000 : 139-149) ومما يستدعي ذكره أن هذه الحاجات خاضعة ونئ للتعلم ، وكل شئ خاضع للتعلم يحدث عن طريق عملية اتصال مقصود أو غير مقصود ، وهذا ما يطلق عليه بالمعلم والمتعلم أو المرسل والمستقبل (نصرالله، 2001 : 102-103). 3.3 .2 اولا: الدراسات التي تناولت الاغتراب النفسي: - بكر (1979): هدف الى التعرف على مستوى مفهوم الذات والاغتراب النفسي لدى طلبة جامعة المستنصرية وعلاقتهما ببعضهما ومعرفة العلاقة بين هذين المتغيرين لدى طلبة الجامعة بشكل عام ولدى الجنسين بشكل خاص، حيث تم بناء مقياس للآغتراب والمتكون من(125) فقرة ومقياس مفهوم الذات المتكون من(76) فقرة، وأستخدم معامل أرتباط بيرسون والآختبار التائي كأجراءات 
من (1】2) سنة و 28\% أكثر من 4 سنوات،و أن الإنترنت بدأ

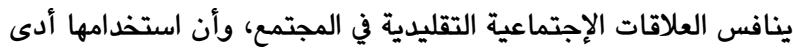
إلى استثمار الشباب لأوقات فراغهم وتعميق معرفتهم و صقل مواهبهم وتنميتها، كما لعب في المشاركة بالأعمال الخيرية والانضمام إلى النوادي .في المقابل انها تركت بعض الآثار السلبية على مستخدميه تمثلت بظهور أعراض الإدمان و خلق بعض الصدمات العاطفية

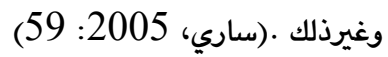
ودراسة ميتال وآخرون Mittal \&et.al2006),2006 هدفت الى التعرّف على مجالات استخدام الإنترنت وعلاقته بالشخصية الشيزويدية المضطربة SPD ، والعلاقة بين استخدام الإنترنت

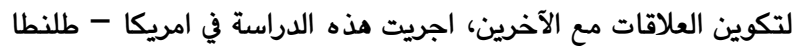
على (69) مراهق ومراهقة، اما الادات التي استخدمها الباحث فكان استبيان والمقابلة ومقياس اضطراب الشخصية ومقياس الذكاء ،وتم الاعتماد على تحليل التباين الثنائي ومريع كاي كوسائل احصائيى

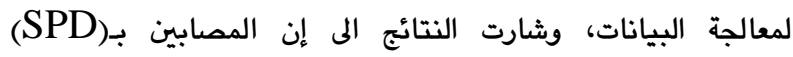

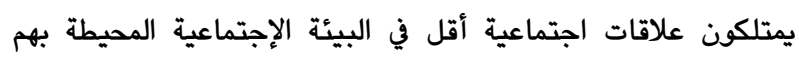
ويجأون للإنترنت للتفاعل الإجتماعي ويتكرارات اكثر مما هو لدى مجموعة (الأسوياء) ، وأن الاشتراك بغرف المحادثة واللعب على لإنى

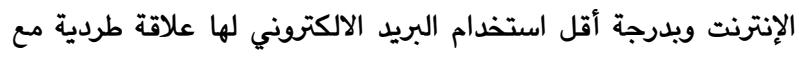

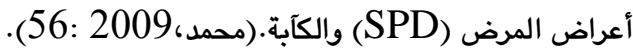

4.3.2مدى الاستفادة من الدراسات السابقه: بعد إطلاع الباحثان على إجراءات ونتائج الدراسات السابقة اتضح وجود جوانب اتفاق وأخرى اختلاف بين تلك الدراسات في بعض الترات التاني إجراءاتها ولغرض بيان ذلك والاستفادة من بعض تلك الجوانب في الدراسة الحالية، وحاول الباحثان توظيف ما توفرت لهما من دراسات سابقة حول متغيري البحث بقدر المستطاع من ناحية الاستفادة من

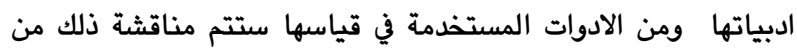

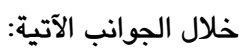

1-1 لأهداف: تباينت اهداف الدراسة الحالية مع الدراسات السابقة .

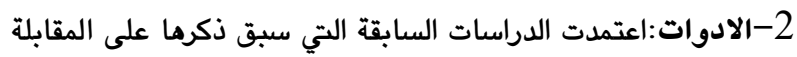

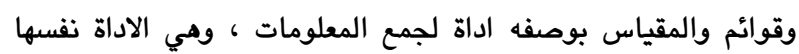

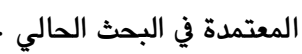
3-عينة الدراسة :كذلك من حيث نوع العينة فقد كانت عينة معظم الدراسات السابقة هي الشباب والمرامقين وطلبة الجامعة كما في دراسة

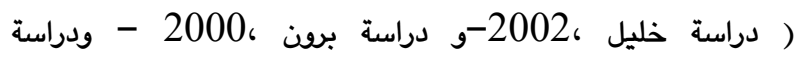
بكر،1979، ) و هي نفس العينة المستخدمة في البحث الحالي . 4-الوسائل الاحصائية: لقد تبين أن أغلب الدراسات السابقة استخدمت في إجراء التحليلات الإحصائية معاملات ارتباط بيرسون

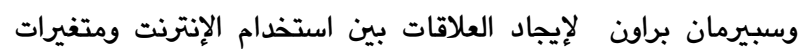

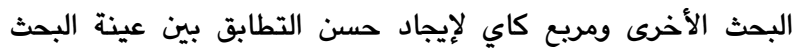

المختلطة كما بينت وجود فرق لصالح الطلبة المسلمين ،كما واوضحت النتائج بوجود علاقة ارتباطية موجبة بين درجة الاغتراب والدرجة الكلية للصحة النفسية (بدير، 2005: 25 25). - ثانيا:دراسات تناولت استخدام الانترنت: دراسة اشتين ولاري(Eastin,Larose,2000):هدفتالى التعرف على مدى استخدام شبكة الانترنت وعلاقته بفعالية الذات للانترنت

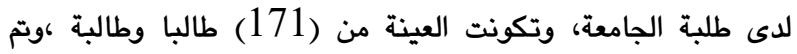
تطبيق مقياس فعالية الذات للانترنت وتحديد مدة الذبرة لاستخدام الانترنت ،ومقياس الضغوط النفسية لشبكة الانترنت ومقياس الضغوط النفسية للحياة .اشارت النتائج الى وجود علاقة ارتباطية قوية ودالة احصائيا بين فعالية الذات للانترنت ومدة الخبرة السابقة لشبكة الانترنت ،والتوقعات الاجتماعية الناتجة عن الانترنت ،وتوقعات المعلومات الشخصية ،و توقعات سلبية كالترفيه الشخصي كما اوضحت وجود علاقة ارتباطية سالبة ودالة احصائيا بين فعالية الذات للانترنت وكل من الضغوط النفسية للحياة و الاكتئاب ،والشعور بالوحدة،وانخفاض الشعور بالمساندة المدركة لدى مدمني استخدام شبكة الانترنت ، كما اشارت النتائج الى انه يمكن التنبؤ بفعالية الذات للانترنت من خلال مدة الخبرة السابقة للانترنت بشرط وجود عامين من الخبرة لتحقيق الفعالية الذاتية فيه ،على العكس من المستخدمين الجدد لانترنت(عبد الهادي ومطر، 2005: 14-15). و دراسة دستمان (Dittmann,2002): هدفت الى التعرف على العلاقة بين استخدام شبكة الانترنت و شعور طلاب الجامعة بالوحدة داني

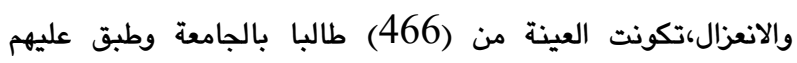
مقياس الشعور بالوحدة و العزلة (UCLA) الصورة الثالثة ،وستبيان لاستخدام شبكة الانترنت .وقد اوضحت النتائج وجود علاقة

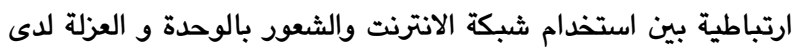

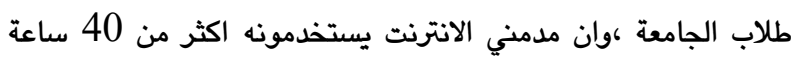
بينما الطالب غير المدمن للانترنت يستخدمه اقل من 40 ساعة اسبوعيا ،كما اوضحت وجود علاقة ارتباطية عكسية بين الشعور بالوحدة و العزلة وعدد السنوات او المدة التي استخدمها الطالب

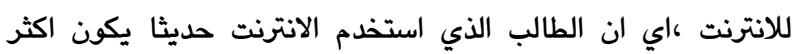

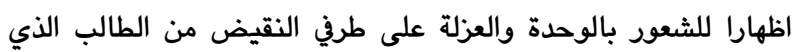

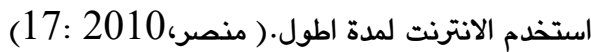

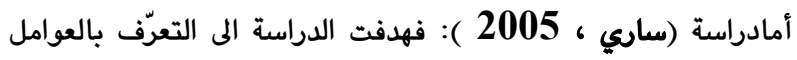

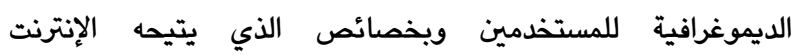
لمستخدميه الشباب. ومقارنة تلك الخصائص بخصائص الاتصال في الإنيات البيئة التي يعيش فيها في القطر على 258 شاب و 214 شابة. اعتمد الباحث على الاستبيان كاداتا للدراسة، واستخدم معامل الارتباط

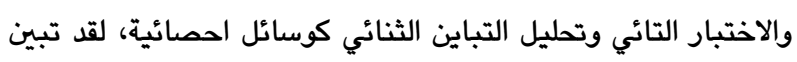
أن حوالي 35٪ بدأو بالاستخدام من أقل من سنتين وحوالي 35٪ 
العلوم بالطريقة العشوائية وينسبة مئوية (10\% ) والجدول (3)

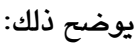
جدول(4): يوضح عينة البحث

\begin{tabular}{|c|c|c|c|c|c|}
\hline \multirow{2}{*}{ المجموع } & \multicolumn{2}{|c|}{ الرابعة } & \multicolumn{2}{|c|}{ الاولى } & لبلمرحلة والب \\
\hline & طالبة & طالب & طالبة & طالب & والاخ \\
\hline 90 & 15 & 15 & 20 & 40 & انساني \\
\hline 67 & 11 & 13 & 18 & 25 & علمي \\
\hline 157 & 26 & 28 & 43 & 66 & المجموع \\
\hline
\end{tabular}

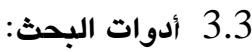
قام الباحثان بإعداد اداتي البحث أولهما أداة استخدام الانترنت

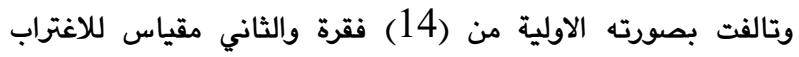

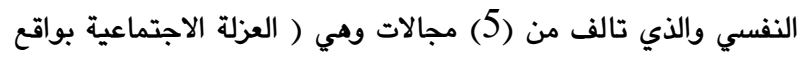

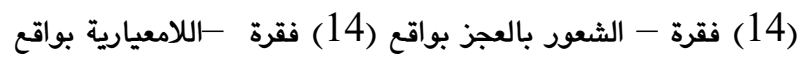

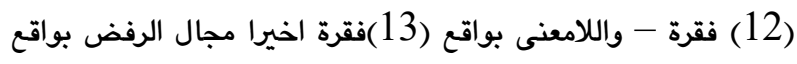

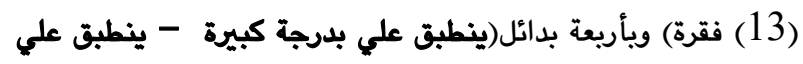

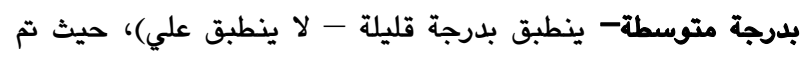

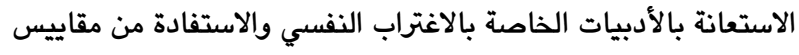

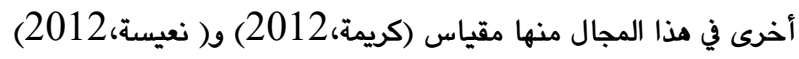
و(شحادة 2012). 1.3.3 الخصائص السيكومترية لمقياسي البحث 1الصدق الظاهري أشار ادجارتون (Edgerton,1949) على أن الصدق يشير إلى الى

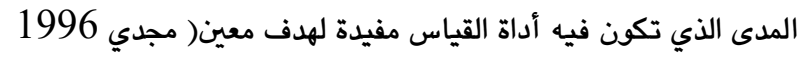

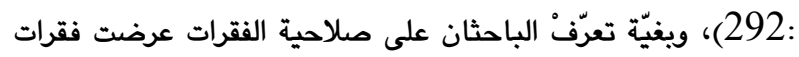
مقياس البحث (الاغتراب النفسي) و(استبانة استخدام الانترنت) على

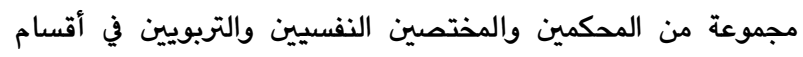
العلوم التربوية والنفسية في جامعتي (دهوك - زاخو ) وفي ضوء آلراء الخبراء والمناقشات التي أجريت معهم أبقى الباحثان على فقرات التي

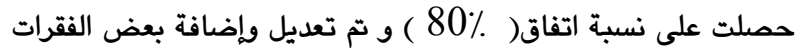

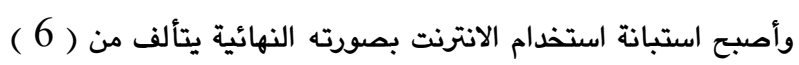

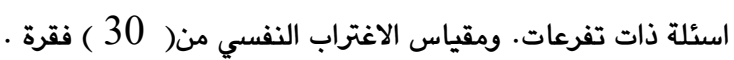

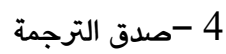
للحصول على بيانات أكثر دقة وعلمية قام الباحثان بترجمة مقياسي

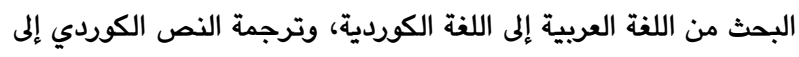
العربية وعرض الباحثان مرة أخرى المقياس على مجموعة من الخبراء

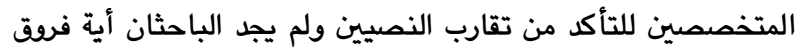
تذكر من حيث المعنى ومن حيث المضمون و بهذا تم التحقق من

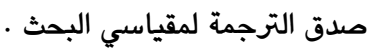
4.3
ومتغيراتها ومجتمع البحث و الاختبار التائي للتحقق من وجود العلاقات بين متغيرات البحث وتحليل التباين. وقد اتفق البحث الحالي مع بعض تلك الدراسات في استخدام معامل الارتباط والاختبار التائي وتحليل التباين كوسائل إحصائية لتحليل البيانات ومعالجتها إحصائيا. 3. الفصل الثالث

1.3 يتضمن هذا الفصل منهجية البحث وإجراءاته: استخدم الباحثان المنهج الوصفي من نوع الارتباط ، وفيه سوف

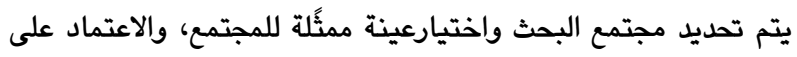
مقاييس ملائمة، واختيار المعالجات الإحصائية اللازمة لتحقيق أهداف

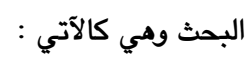

أ- مجمل أعداد طلبة جامعة زاخو

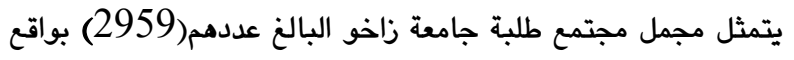

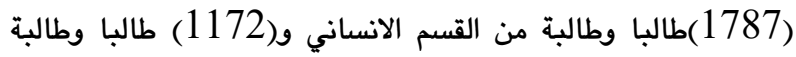

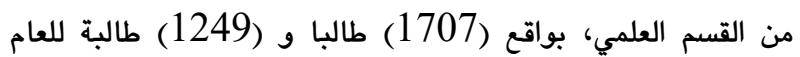

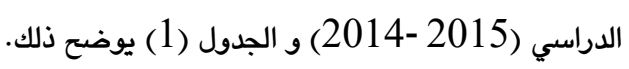
جدول (2) :يوضح توزيع مجمل مجتمع طلبة الجامعة

\begin{tabular}{|c|c|c|c|}
\hline المجموع & طالبة & طالب & القسم/الطلبة / \\
\hline 1787 & 762 & 1025 & انساني \\
\hline 1172 & 490 & 682 & علمي \\
\hline 2959 & 1252 & 1707 & المجموع \\
\hline
\end{tabular}

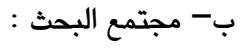

بما أن البحث يتحدد بطلبة المرحلة الأولى والرابعة ، تم استبعاد

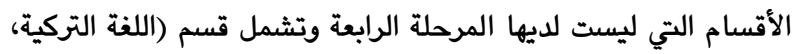

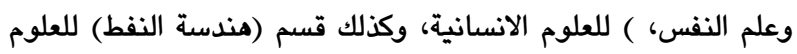

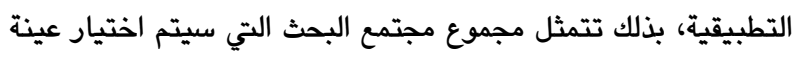

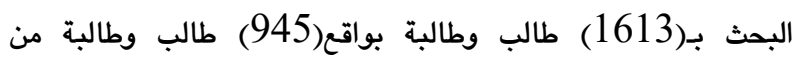

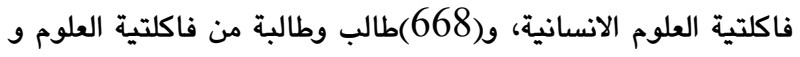

$$
\text { الجدول(2) يوضح ذلك : }
$$

\begin{tabular}{|c|c|c|c|c|c|}
\hline \multirow{2}{*}{ المجموع } & \multicolumn{2}{|c|}{ الرابعة } & \multicolumn{2}{|c|}{ الاولى } & كالهرحلة وال \\
\hline & طالبة & طالب & طالبة & طالب & \\
\hline 945 & 145 & 145 & 252 & 403 & انساني \\
\hline 668 & 111 & 130 & 175 & 252 & علمي \\
\hline 1613 & 256 & 275 & 427 & 655 & المجموع \\
\hline
\end{tabular}
جدول (3) : يوضح توزيع مجتمع البحث

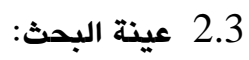
بعد جمع المعلومات حول مجتمع البحث تم اختيار عينة ممثلة

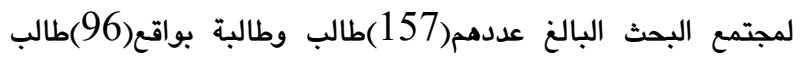
وطالبة من فاكلتية العلوم الانسانية ،و(67) طالب وطالبة من فاكلتية 
التائي لعينيتين مستقلتين، ومعاملات الإرتباط) باستخدام برنامج( SPSS).

\section{4. عرض النتائج ومناقشتها}

بعد تطبيق أدوات البحث وإجراء التحليلات الإحصائية اللازمة للبيانات المأخوذة من عينة البحث ستعرض النتائج التي تم التوصل إليها في البحث الحالي على وفق الأهداف المحددة مسبقا ومن ثم سيتم مناقشة تلك النتائج وكآلاتي:

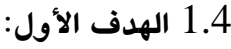
التعرف على مستوى الشعور بالاغتراب النفسي لدى أفراد العينة ككل:أوضحت نتائج البحث أن المتوسط الحسابي لمجموع افراد عينة البحث بلغ (60.80) درجة ويانحراف معياري قدره (13.31) درجة وعند المقارنة بالمتوسط الحسابي الفرضي للمقياس البالغ (75) درجة تبيّن أنها أقل. وللتحقق من ذلك تم استخدام الاختبار التائي (t.test) لعينة واحدة وتبيّن ان القيمة التائية المحسوية تساوي (13.63) درجة وهي أعلى من القيمة التائية الجدولية (1.96) عند مستوى دلالة (0.05) ويدرجة حرية (156) وتشير مذه النتيجة إلى عدم وجود الشعور بالإغتراب النفسي

عند أغلب أفراد عينة البحث كما موضح في الجدول (5).
يعد الثبات من العوامل المهمة أو الخصائص الواجب توافرها لصلاحية استخدام أي أداة اختبار (الكبيسي، 2006 :200). ويقصدبالثبات بأنه مدى الاتساق بين البيانات التي تجمع عن طريق إعادة تطبيق المقياس نفسه على الأفراد نفسهم وتحت الظروف نفسها (ملحم ، 2005 :308) وللتأكد من ثبات مقياس البحث استخدم الباحثان طريقة إعادة الاختبار (Test - Retest)، ويؤكد فيركسون(1991) انه لإستخراج الثبات بهذه الطريقة يتم تطبيق

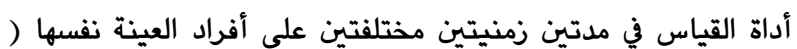
فيركسون، 1991 :527) ولاستخراج الثبات بهذه الطريقة طبيق الباحثان المقياس على عينة من أفراد البحث بلغ عددما (30) طالب وطالبة في وكانت المدة الزمنية بين التطبيق الأول والتطبيق الثاني خمسة عشرة يوما، بتاريخ( 2014/12/9 يوم الثلاثاء إلى لى

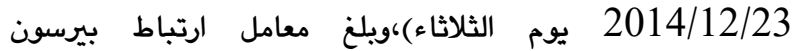
Pearson للثبات( عودة ،الخليلي 1988 :146 ). خامسا/الوسائل الإحصائية: تم استخراج (المتوسطات الحسابية، والانحرافات المعيارية، والإختبار التائي للعينة الواحدة، والإختبار

جدول ( 5 ) : يوضح التحقق من شعور أفراد عينة البحث بالإغتراب النفسي

\begin{tabular}{|c|c|c|c|c|c|c|c|}
\hline درجة الحرية & مستوى الدلالة & القالجدولية القيمة & القحسية التائية & الفرضي الوسط & الالحراف & الوسطابي & عدد أفراد العينة \\
\hline 156 & 0.05 & 1.96 & 13.63 & 75 & 13.31 & 60.80 & 157 \\
\hline
\end{tabular}

الجدول (8): يوضح النسب المئوية لأفراد عينة البحث ككل للشعور

\begin{tabular}{|c|c|c|c|c|}
\hline \multicolumn{5}{|c|}{ بالإغتراب النفسي } \\
\hline الانحراف & الوسط & النسب & العدد الع & الشعور بالاغتراب \\
\hline المعياري & الصسابي & المئوية & & النفسي \\
\hline 6.32 & 84.52 & 15.44 & 21 & يشعرون \\
\hline & & & & بالاغتراب النفسي \\
\hline 9.84 & 57.14 & 84.56 & 136 & لالاغتراب النفسي \\
\hline
\end{tabular}

يعزى الباحثان ذلك إلى الإختلاف في أساليب التنشئة الإجتماعية والبيئات الثقافية التي تشرب منها أفراد عينة البحث، وأن نسبة اللّين يشعرون بالاغتراب النفسي تقع ضمن الحيز الطبيعي أو التوزيع الإعتدالي الطبيعي حسب رأي الباحثان وأنه ليس هناك مجتمع مثالي

خالي من المشاكل والعيوب. 3.4 الهدف الثالث من الثنالث
ويعزى الباحثان ذلك إلى تفتح وإطلاع المجتمع على أساليب التنشئة الإجتماعية من خلال القنوات الإعلامية وقنوات الإتصال الحديثة وإمكانية الإستفادة منها، وحث الاساتذة لاستخدام أساليب تربوية حديثة في تنمية شخصية الطلبة من خلال استخدام طريقة التعليم التعاوني والمناقشة فيما بين الطلبة. : 2.4 الهدف الثاني: التعرف على النسب المئوية لدى أفراد عينة البحث من الذّين يشعرون بالإغتراب النفسي من عدمه::أظهرت النتائح أن حوالي (15.44\% ) من المجموع الإجمالي لأفراد عينة البحث يشعرون

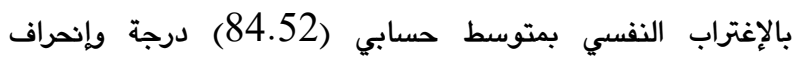
معياري(6.32). في مقابل حوالي( \% 84.56) منهم لايشعرون بذلكبمتوسط حسابي(57.14) درجة وإنحراف معياري (9.84) كما

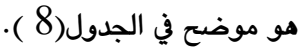

تعرّف الفروق بين أفراد عينة البحث ككل على مقياس الشعور بالإغتراب النفسي تبعا لمتغير الجنس والقسم الدراسي والسكن الجامعي::بعد استخراج الوسط الحسابي والإنحراف المعياري ،وإستخدام الإختبار التائي(t-test) لعينيتين 
مستقلتين توصل الباحثان إلى عدم وجود فروق بين الطلبة بشكل عام الدراسي، السكن الجامعي، استخدام الإنترنت) وكما هو موضح في على مقياس الشعور بالإغتراب النفسي تبعا لمتغير( الجنس، القسم الجدول(7). الجدول(7): يوضح الأوساط الحسابية والإنحرافات المعيارية والاختبار التائي للشعور بالإغتراب النفسي حسب متغيرات البحث(الجنس، القسم الدراسي، المرحلة الدراسية، السكن الجامعي، استخدام الإنترنت)

\begin{tabular}{|c|c|c|c|c|c|c|c|}
\hline درجة الحرية & مستوى الدلالة & قيمة التاء & قيمة التاء & انحراف معياري & وسط حسابي & العدد & عينة البحث حسب \\
\hline \multirow{2}{*}{155} & \multirow{2}{*}{0.05} & \multirow{2}{*}{1.96} & \multirow{2}{*}{1.155} & 13.13 & 61.85 & 91 & الذكور \\
\hline & & & & 13.53 & 59.36 & 66 & الإناث \\
\hline \multirow{2}{*}{155} & \multirow{2}{*}{0.05} & \multirow{2}{*}{1.96} & \multirow{2}{*}{0.788} & 12.30 & 60.10 & 93 & انساني \\
\hline & & & & 14.70 & 61.81 & 64 & علمي \\
\hline \multirow{2}{*}{155} & \multirow{2}{*}{0.05} & \multirow{2}{*}{1.96} & \multirow{2}{*}{1.05} & 14.35 & 60.03 & 106 & مرحلة الأولى \\
\hline & & & & 10.81 & 62.41 & 51 & مرحلة الرابعة \\
\hline \multirow{2}{*}{155} & \multirow{2}{*}{0.05} & \multirow{2}{*}{1.96} & \multirow{2}{*}{1.845} & 14.09 & 62.6 & 86 & يسكن القسم الداخلي \\
\hline & & & & 12.07 & 58.7 & 71 & لايسكن القسم الداخلي \\
\hline \multirow{2}{*}{155} & \multirow{2}{*}{0.05} & \multirow{2}{*}{1.96} & \multirow{2}{*}{0.788} & 13.42 & 60.60 & 146 & يستخدم الانترنت \\
\hline & & & & 12.01 & 63.82 & 11 & لايستخدم الانترنت \\
\hline
\end{tabular}

4.4 التعرف على نسبة استخدام الانترنت وعلاقته بالإغتراب النفسي لدى أفراد العينة ككل:توصل الباحثان إلى أن حوالي (92\%) من إجمالي أفراد عينة البحث يستخدمون الإنترنت ويمتوسط حسابي أقل للشعور بالإغتراب النفسي من عينة الذين لايستخدمونها والتي تشكل نسبتهم حوالي

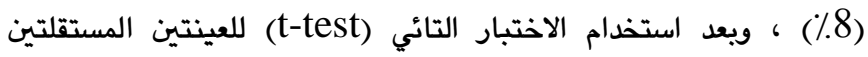
أظهرت أن القيمة التائية المائ (t-test) المحسوية أقل من القيمة التائية) (test

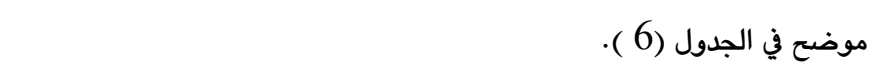

النتيجة أعلاه يشير إلى أن الشعور بالإغتراب لايرتبط بفئة دون أخرى لانيت

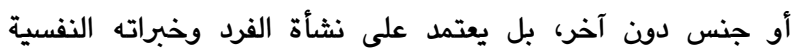
الإجتماعية والمحيط الثقافي الذي هو فيه ومدى وضوح ومرونة المعايير والأدوار الإجتماعية ، لذا يعزى الباحثان إلى أن الأستقرار الإجتماعي والأقتصادي وتطور المفاهيم التربوية لها دود في تنمية نفسيات أفراد عينة البحث بشكل عام وإستفادتهم من التربية والتعليم السابق لهم.

\begin{tabular}{|c|c|c|c|c|c|c|c|c|}
\hline 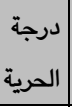 & الدلالة & | & | & المعياري & الوسط الحسابي & |النسب المئوية & | العدد & عينة البحث عسب استخدام \\
\hline \multirow{2}{*}{155} & \multirow{2}{*}{0.05} & \multirow{2}{*}{1.96} & \multirow{2}{*}{0.788} & 13.42 & 60.60 & $\% 92.47$ & 146 & يستخدم \\
\hline & & & & 12.01 & 63.82 & $\% 7.53$ & 11 & لايستخدم \\
\hline
\end{tabular}

جدول ( 6): يوضح نسبة استخدام عينة البحث ككل للإنترنت وعلاقته بالإغتراب النفسي

كما أظهرت النتائج أن الوسط الحسابي للّذين يسكنون القسم الداخلي أعلى من الوسط الحسابي للذين لايسكنون القسم الداخلي، وأن الوسط الحسابي للذين يستخدمون الإنترنت أعلى من الوسط الحسابي للّذين لايستخدمونها و وللتحقق من الفروق استخدم الباحثان الإختبار التائي(t-test) لعينتين مستقلتين تبيّن أن القيمة التائية (t-test) لعينة الجنس والقسم الدراسي والمرحلة الدراسية واستخدام الإنترنت أقل من القيمة التائية (t-test) الجدولية .وهذا يدل على عدم وجود فروق بين تلك المتغيرات الجنس والشعور بالإفتراب النفسي، وأن

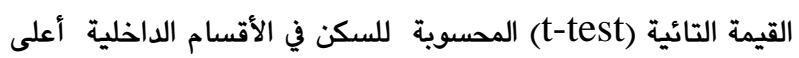
من القيمة التائية (t-test) الجدولية ولصالح عينة الوسط الحسابي الأعلى( اللّذين يسكنون في القسم الداخلي) كما موضح في الجدول(9).
ويعزى الباحثان ذلك إلى أن الإنترنت وسيلة للتواصل الإجتماعي تساعد الفرد في تكوين علاقات إجتماعية عبر الأثير، حيث تجتاز العوائق المكانية والزمانية ويعض العادات والمعايير الإجتماعية مما ينمي الثقة بالنفس عند الإستخدام السليم لها. 5.4 الهدف الخامس: تعرف الفرق بين أفراد عينة البحث من الذين يشعرون بالإغتراب النفسي تبعا لمتغير: (الجنس-القسم الدراسي-المرحلة الدراسيةالسكن الجامعي-استخدام الإنترنت):أظهرت النتائج أن الوسط

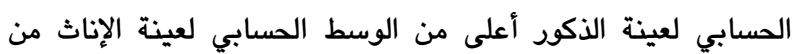
الذين يشعرون بالإغتراب النفسي، وأن الوسط الحسابي للقسم العلمي أعلى من القسم الإنساني أما بالنسبة للمرحلة الدراسية فتبيّن أن

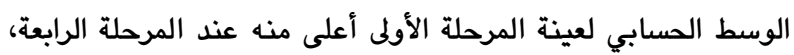




\begin{tabular}{|c|c|c|c|c|c|c|c|c|}
\hline درجة الحرية & مستوى الدلالة & التاء الجدولية & التاء & الالحرياف & الوسط الحسابي & 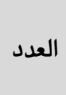 & \multicolumn{2}{|c|}{ عينة البحث حسب المتغير } \\
\hline \multirow{2}{*}{19} & \multirow{2}{*}{0.05} & \multirow{2}{*}{2.09} & \multirow{2}{*}{0.51} & 6.35 & 85.16 & 12 & ذكور & \multirow{2}{*}{ الجنس } \\
\hline & & & & 6.92 & 83.66 & 9 & إناث & \\
\hline \multirow{2}{*}{19} & \multirow{2}{*}{0.05} & \multirow{2}{*}{2.09} & \multirow{2}{*}{1.47} & 5.70 & 82.40 & 10 & انساني & \multirow{2}{*}{ القسم الدراسي } \\
\hline & & & & 6.78 & 86.45 & 11 & علمي & \\
\hline \multirow{2}{*}{19} & \multirow{2}{*}{0.05} & \multirow{2}{*}{2.09} & \multirow{2}{*}{0.68} & 7.38 & 85.21 & 14 & مرحلة الاولى & \multirow{2}{*}{ المرحلة الدراسية } \\
\hline & & & & 4.30 & 83.14 & 7 & مرحلة الرابعة & \\
\hline \multirow{2}{*}{19} & \multirow{2}{*}{0.05} & \multirow{2}{*}{2.09} & \multirow{2}{*}{2.65} & 6.47 & 86.60 & 15 & يسكن في القسم داخلي & \multirow{2}{*}{ السكن الجامعي } \\
\hline & & & & 2.25 & 79.33 & 6 & لا يسكن في القسم داخلي & \\
\hline \multirow{2}{*}{19} & \multirow{2}{*}{0.05} & \multirow{2}{*}{2.09} & \multirow{2}{*}{0.86} & 6.51 & 84.80 & 20 & يستخدم الانترنت & استخدام \\
\hline & & & & 0 & 79.00 & 1 & لايستخدم الانترنت & الإنترنت \\
\hline
\end{tabular}

العينة يستخدمون الإنترنت من(1 - 2) ساعة في اليوم الواحد وأن

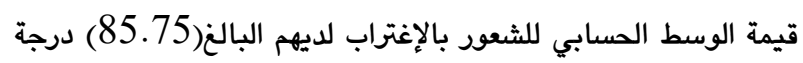

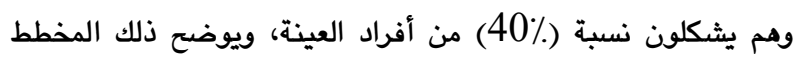
البياني( ومث يش

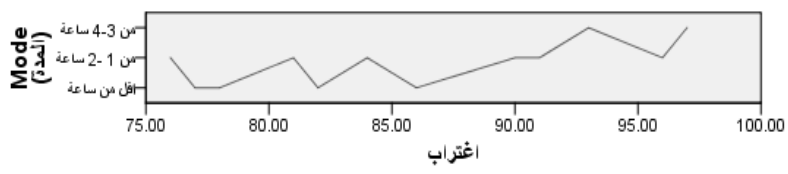

المخطط البياني (2): يوضح العلاقة بين شعور الفرد بالإغتراب النفسي وعلاقته بمدة إستخدام الإنترنت

ويبدو من النتيجة أعلاه أنه كلما كان شعور الفرد بالإغتراب أشد كلما حاول تعويض ذلك بوسيلة ما قد تكون واقعية أم غير واقعية، لذا

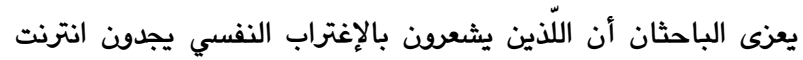

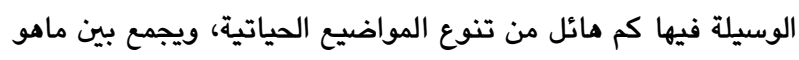

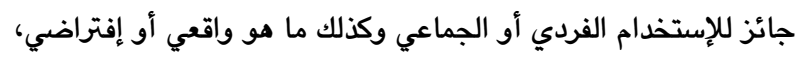
وما هو مقبول إجتماعيا أو غير مقبول.

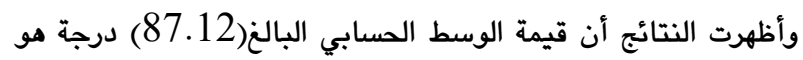

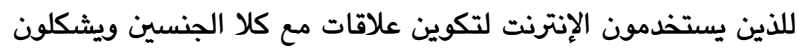

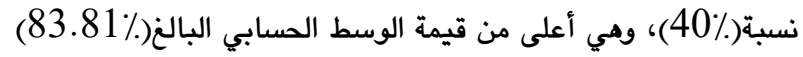

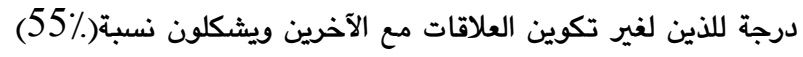
من أفراد العينة، ويوضح ذلك المخطط البياني(3).

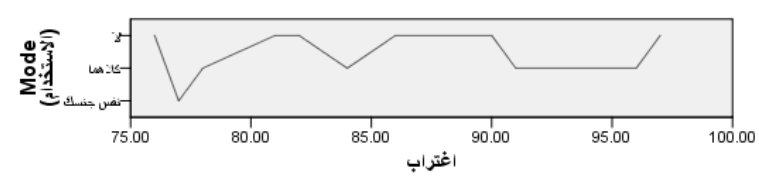

ويعزى الباحثان ذلك إلى أن بعد أفراد عينة البحث عن ذويهم

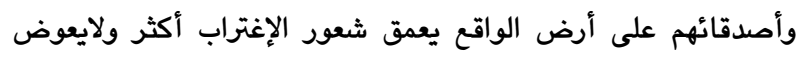

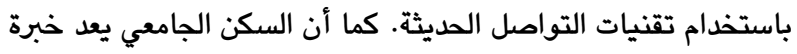

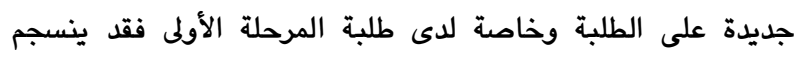
البعض مع ذلك وقد لا ينسجم البعض الآخر مما يولد شعورا إجتماعيا

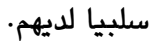
6.4 الهدف السادس: تعرّف العلاقة لدى أفراد عينة الذين يشعرن بالإغتراب النفسي وإستخدامهم الانترنت حسب المتغيرات التي وردت في أداة البحث لإستخدام الإنترنت:أظهرت نتائج المعالجات الإحصائية لعينة الذين

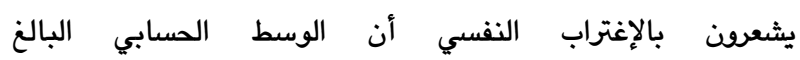

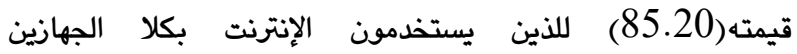
(الكومبيوتر والموبايل) أعلى من الذين يستخدمونها بأحد الأجهزة الأنهانين الكومبيوتر بقيمة (78.00)أو الموبايل ب (18.11) كما هو موضح الكين

في المخطط البياني(1)

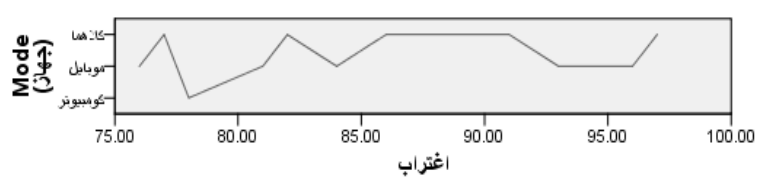

المخطط البياني(1): يوضح العلاقة بين الإغتراب النفسي و الجهاز الذي يستخدم به الفرد الإنترنت

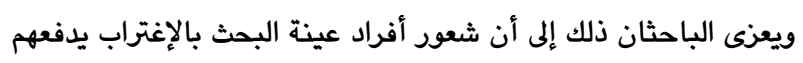

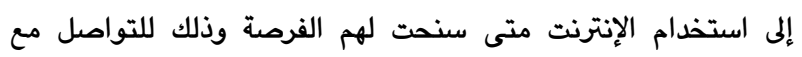

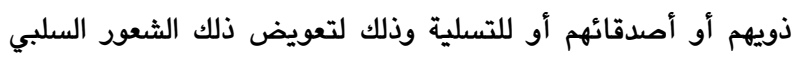
مما يؤدي إلى تعلق أكثر بها.

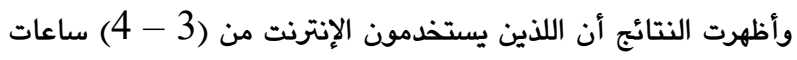

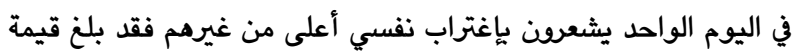

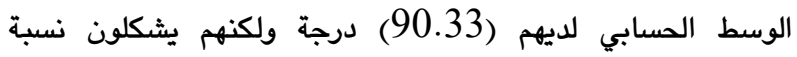

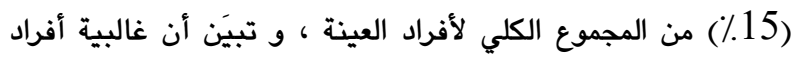


بالفتور الإجتماعي عند الفرد وقد يكون له أثرا رجعيا على تحصيله

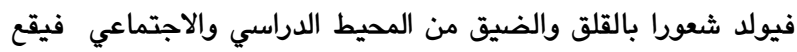
الشخص في دوامة مفرغة. وأظهرت نتائج البحث أن الوسط الحسابي البالغ(86.86) درجة لعينة الذين يستخدمون الإنترنت لأغراض غير تكوين علاقات الصداقة مع الآخرين ويشكلون نسبة(\%)

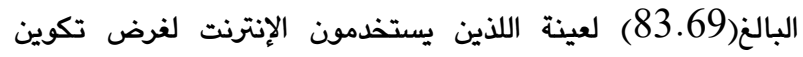

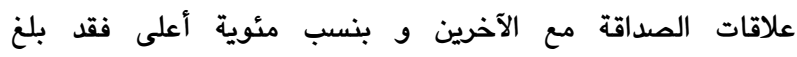
نسبتهم(:66.66)، ويوضح ذلك المخطط البياني(6 ).

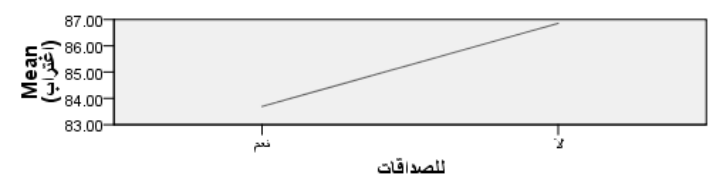

المخطط البياني(6): يوضح العلاقة بين الشعور بالإغتراب النفسي

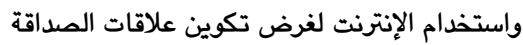

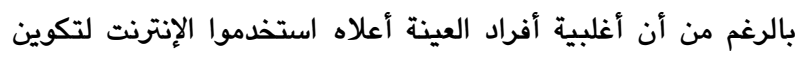

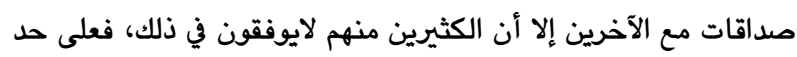

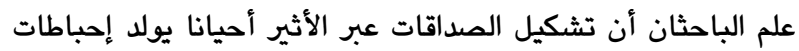

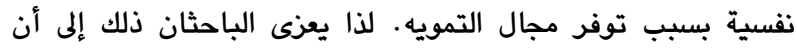

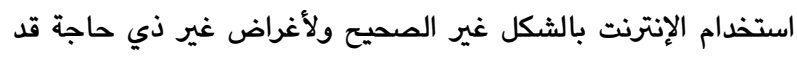

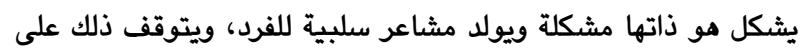

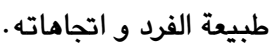
أما بالنسبة لمدى شعور الفرد بالتقبل من قبل عائلته بعد إستخدام

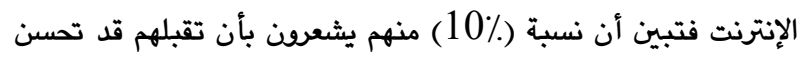

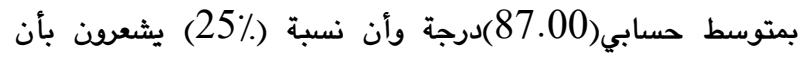
مدى تقبلهم قد قل ويمتوسط حسابي(850)

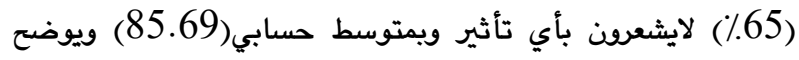

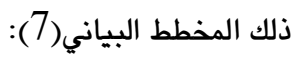

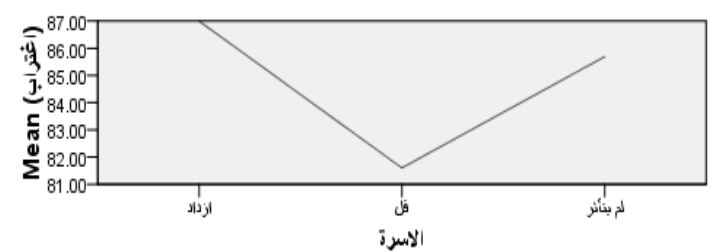

المخطط البياني(7): يوضح العلاقة بين الشعور بالإغتراب النفسي وتقبله من قبل أسرته بعد إستخدامه الإنترنت

أما بالنسبة لمدى شعور الفرد بالتقبل من قبل أصدقائه بعد إستخدام

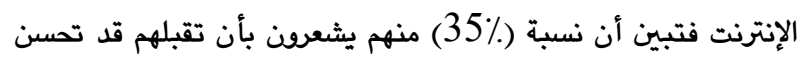

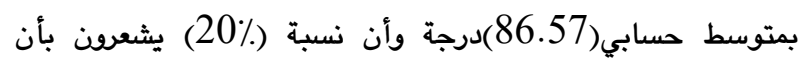
مدى تقبلهم قد قل ويمتوسط حسابي(78.00) بينما أن نسبة
المخطط البياني(3): يوضح العلاقة بين الشعور بالإغتراب النفسي

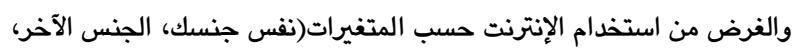
كلاهما، لان

وتشير هذه النتيجة إلى أن الذين يشعرون بإلاغتراب النفسي بحاجة

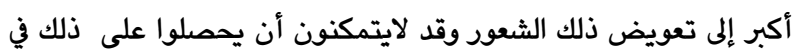
واقعهم الإجتماعي فيميلون إلى إستخدام الإنترنت اكثر من غيرها لأنها

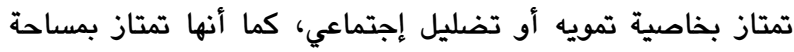

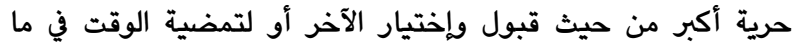
أما بالنسبة لإستخدام الإنترنت لأمور التسلية فتبيّن أن الوسط

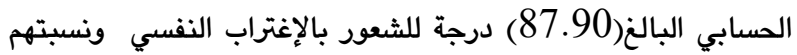

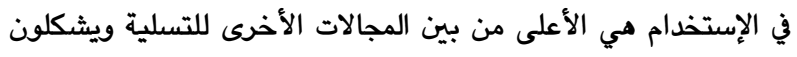
حوالي(55) من إجمالي مجموع العينة، ويوضح ذلك الإنى المخطط

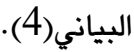

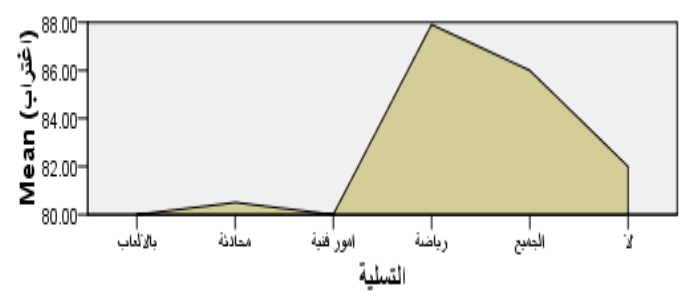

المخطط البياني(4): يوضح العلاقة بين الشعور بالإغتراب النفسي وعلاقته بإستخدام الإنترنت لغرض التسلية

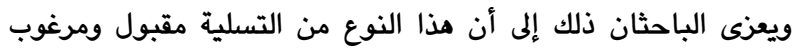
إجتماعيا ويكون وسيلة غير مباشرة لإنشاء وتوطيد العلاقات

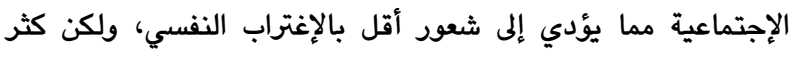

الإنغماس فيها قد يولد إدمانا نفسيا وتعطي حينها أثرا رجعيا.

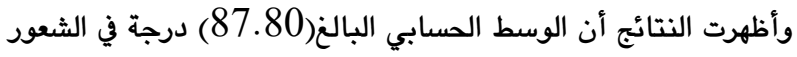

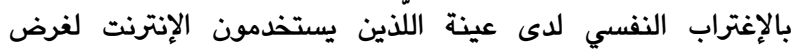

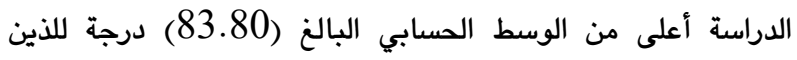

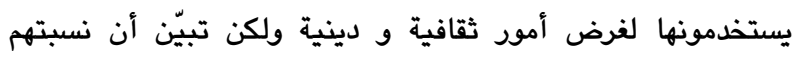
المئوية البالخ(25\%) أقل من نسبة اللذين يستخدمون لأمور ثقافية والبالغ (75\%) من إجمالي أفراد العينة، ويوضح ذلك المخطط

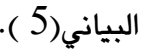

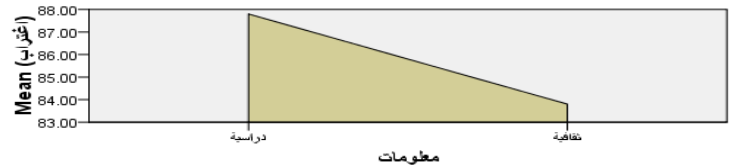

المخطط البياني(5): يوضح العلاقة بين الشعور بالإغتراب النفسي

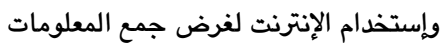

ويغتقد الباحثان بان استخدام الإنترنت لاغراض الدراسة يكون على الإنى حساب العلاقات الإجتماعية والإنتماء الإجتماعي مما يولد شعورا 
المخطط البياني(10): يوضح العلاقة بين الشعور بالإغتراب النفسي و

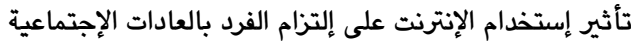

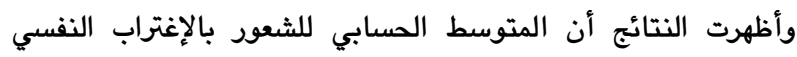

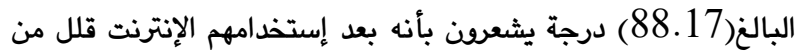
امتمامهم بمشاعر الآخرين ويشكلون نسبة(30\%) أعلى من المتوسط بانه

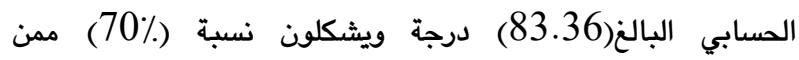
لايشعرون بذلك، و يوضح ذلك المخطط البياني(11 ).

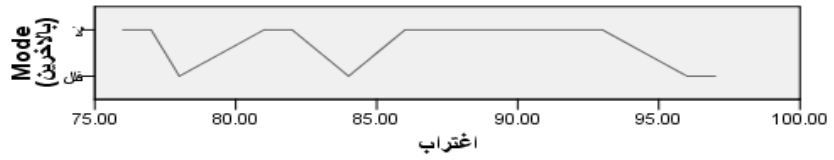

المخطط البياني(11): يوضح العلاقة بين الشعور بالإغتراب النفسي و تأثير إستخدام الإنترنت على إهتمام الفرد بشعور الآخرين

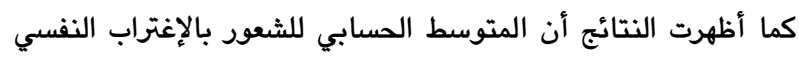

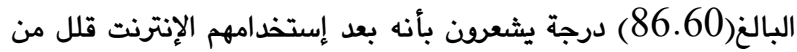

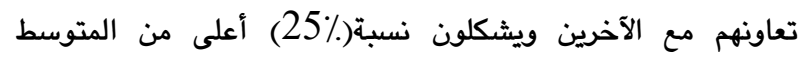

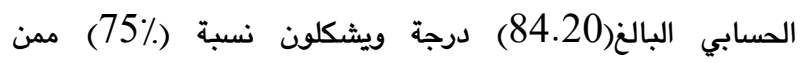
لايشعرن بذلك، و يوضح ذلك المخطط البياني(12).

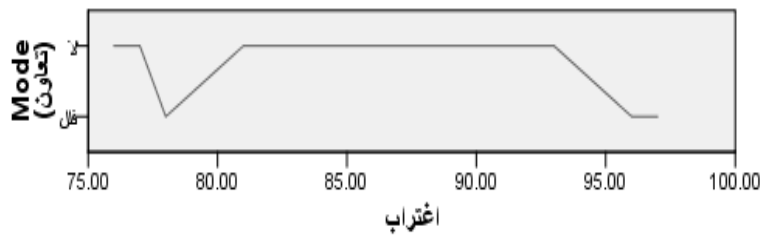

المخطط البياني(12): يوضح العلاقة بين الشعود بالإغتراب النفسي و تأثير إستخدام الإنترنت على تعاونه مع الآخرين

وتبيّن من النتائج أن المتوسط الحسابي للشعور بالإغتراب النفسي

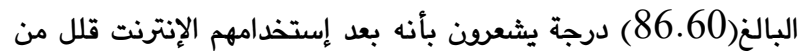

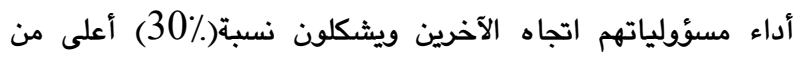
المتوسط الحسابي البالغ(84.20) درجة ويشكلون نسبة (70\%) ممن لايشعرن بذلك، و يوضح ذلك المخطط البياني(13 ).

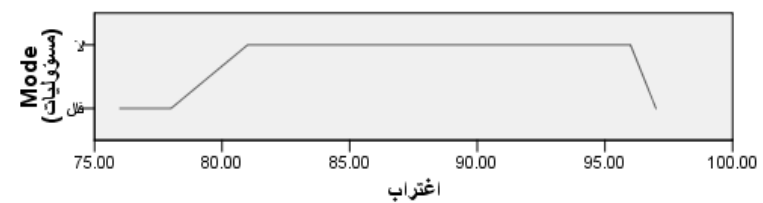

المخطط البياني(13): يوضح العلاقة بين الشعور بالإغتراب النفسي و تأثير إستخدام الإنترنت على مسؤولياته الإجتماعية

وتبيّن من النتائج أن المتوسط الحسابي للشعور بالإغتراب النفسي

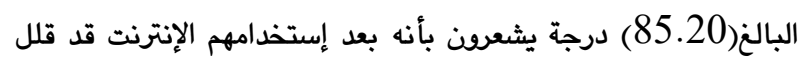

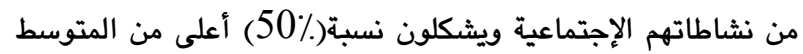

(45\%) لايشعرون بأي تأثير ويمتوسط حسابي(86.44) ويوضح ذلك المخطط البياني(8 ) :

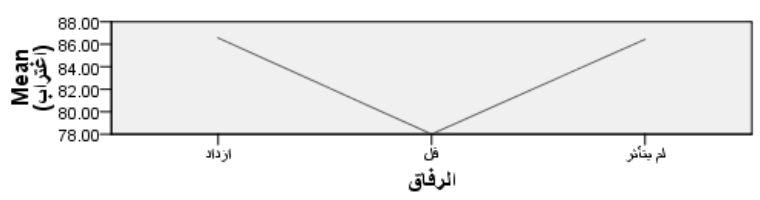

المخطط البياني(8): يوضح العلاقة بين الشعور بالإغتراب النفسي وتقبله من قبل أصدقائه بعد إستخدامه الإنترنت

أما بالنسبة لمدى شعور الفرد بالتقبل من قبل أقربائه بعد إستخدامه

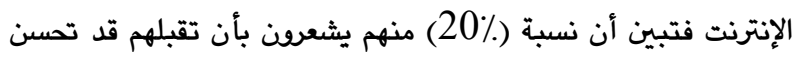
بمتوسط حسابي(85.00)درجة وأن نسبة (35\%) يشعرون بأن مدى تقبلهم قد قل ويمتوسط حسابي(82.71) بينما أن نسبة (45٪) لايشعرون بأي تأثير ويمتوسط حسابي(86.33) و يوضح ذلك المخطط البياني(9 ) :

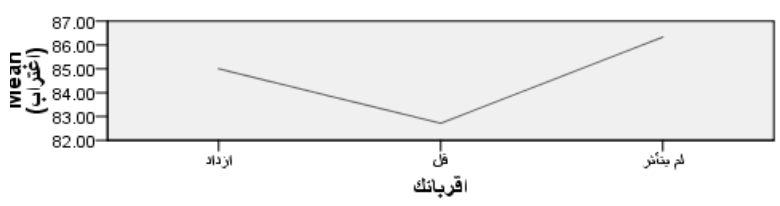

المخطط البياني(9): يوضح العلاقة بين الشعور بالإغتراب النفسي وتقبله من قبل أقرباءه بعد إستخدامه الإنترنت

وتعطي نتائج شعور أفراد عينة البحث أعلاه حول مدى تقبلهم من بن إسند قبل ذويهم وأصدقائهم بعد استخدامهم للإنترنت مؤشرا سلبيا لأن أغلبية أفراد العينة أقرو بعدم تأثير استخدام الإنترنت على تحسن شعورهم بتقبلهم من محيطهم الإجتماعي وتتراوح نسبتهم بين

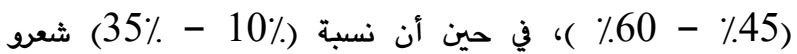
بالتحسن. ويعزى الباحثان ذلك إلى أن أغلبية أفراد هذه العينة لم يستثمروا استخدامهم للإنترنت في مجالات تحسن العلاقات الإجتماعية بالشكل السليم وذلك إما لعدم قدرتهم في توظيف ذلك أو بسبب الإهمال وعدم الشعور بالمسؤولة نحو مجتمعهم. أما بالنسبة لمدى شعور أفراد عينة اللذين لديهم إغتراب نفسي بتأثيرات إستخدام الإنترنت على إلتزام بالقيم الإجتماعية بعد

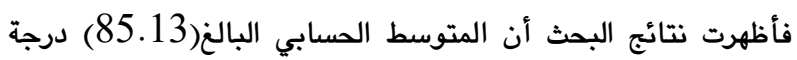
يشعرون بأنها أثرت سلبيا على إلتزامهم بالعادات الإجتماعية ويشكلون نسبة(40\%) أعلى من المتوسط الحسابي البالغ(84.58) درجة ويشكلون نسبة(60\%) من اللّين لايشعرون بذلك، ويوضح ذلك المخطط البياني(10) - (10).

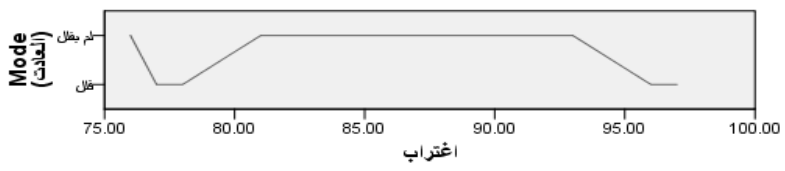


بتاثير سلبي او لم يشعروا باي تاثير في تقبلهم مع محيطهم الاجتماعي

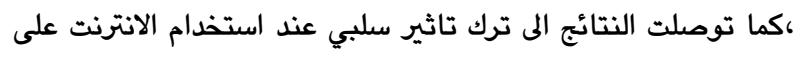
التزامهم بالعادات الاجتماعية واهتمامهم بمشاعر الاخرين والتعاون معهم وكذلك على مسؤولياتهم ونشاطاتهم الاجتماعية. التوصيات :قام الباحثان بتقديم بعض التوصيات للجهات المعنية بالاعتماد على نتائج البحث: 1. قيام اساتذة الجامعات بتوعية الطلبة بمفهوم العولمة الايجابيات والسلبيات حتى يتمكنوا من الحفاظ على هويتهم وان يلتزموا بتعاليم الدين الذي يعتبر وقاية لهم من الوقوع بالاغتراب النفسي.

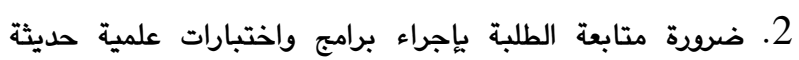
سنويا لمعرفة مستوى شعور طلاب الجامعة بالاغتراب و توجيههم براء بالحلول المناسبة للتخفيف من اثاره. 3. الاهتمام بالمحاضرات والندوات التوعوية التي تشمل على مواضيع من التهاره التي تبصر الطلاب وتنور لهم طريق المستقبل بهدف تحقيق التكيف النفسي والاجتماعي والاكاديمي لهم مما يقلل من الاغتراب النفسي .

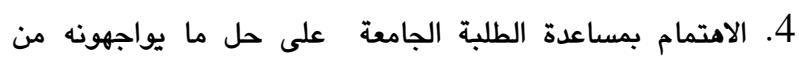
مشكلات حتى لا تكون سببا يؤدي بهم الى العزلة و الشعور بالاغتراب. 5. ضرورة وجود رقابة اسرية و توجيه الابناء نحو الاستخدام الامثل

6. ينبغي تكثيف حملات التوعية وغرس سلوك الدين والتنشئة الاجتماعية في نفوس الشباب في المجتمع •

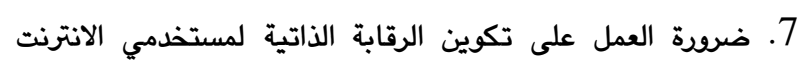
وتوجيه الطلبة نحو الامثل للانترنت في الجامعة .

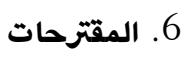

\section{يقدم الباحثان مجموعة من المقترحات للباحثين مستقبلا و ذلك لاجراء دراسات كالاتي :} 1. اجراء دراسة مماثلة على طلبة المرحلة الاساسية. 2. الشعور بالاغتراب النفسي و علاقته بالسلوك السلبي كالتدخين والانحرافات السلوكية لدى طلبة الجامعة . 3. الشعور بالاغتراب النفسي وعلاقته بصنف المهن والاعمال الحياتية. 4. الشعور بالازمات النفسية كالخجل و القلق واستخدام الانترنت لدى المراهقين - المت 5. علاقة الامراض النفسية كالكابة ، الفصام..باستخدام الانترنت

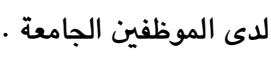

\section{7. - قائمة المصادر}

1. ابراهيم،خالدة(2007)الاغتراب النفسي وعلاقته بالوحدة النفسية لدى طالبات الاقسام الداخلية في جامعة بغداد،المؤتمر الدولي الثامن عشر لكليات والاقسام لكلية التربية الرياضية في العراق.
الحسابي البالغ(84.40) درجة ويشكلون نسبة (50\%) ممن لايشعرون بذلك، و يوضح ذلك المخطط البياني( 14).

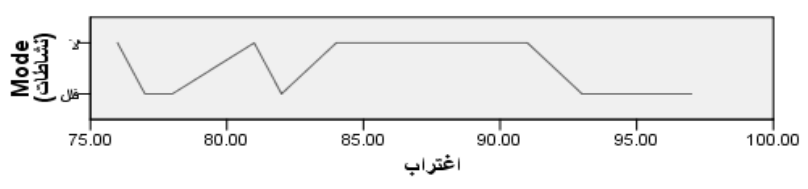
المخطط البياني(14): يوضح العلاقة بين الشعور بالإغتراب النفسي وتأثير إستخدام الإنترنت على نشاطاته الإجتماعية

وتشير النتائج أعلاه إقرار أفراد عينة البحث الذّين لديهم شعود ألعلى بالإغتراب النفسي من غيرهم بتأثيرات إستخدام الإنترنت عليهم وتتراوح نسبهم بين(25 - 250) من إجمالي تلك العينة. ويالرغم من أن هذه النسب تعطي مؤشرا سلبيا لأن المجتمع الجامعي التعليمي بشكل عام ينمي في أعضائها روح التقبل والتسامح ورحح التضحية والتعاون والإلتزام بالمعايير الإجتماعية ولكن رغم ان الإنترنت تركت تأثيرات سلبية عليهم ويتوقف ذلك على الغاية من

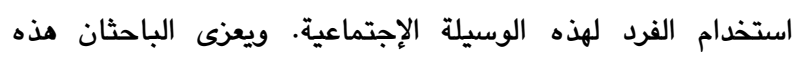
التأثيرات بين أفراد هذه العينة إلى نمط التربية التي ينشأ عليها الفرد إضافة إلى غياب الرقابة الذاتية للفرد عند البعض عند استخدامهم لهذه الوسيلة كما لا نستبعد تأثيرات صعويات التكيف الإجتماعي عند البعض حينما يتغير بيئتهم الثقافية الإجتماعية فالإنتقال من دائرة المدارس ذات التعليمات والتوجهات الإنضباطية إلى الدائرة الجامعية ذات التوجهات التحرية والإنفتاحية يولد لدى البعض شعورا بالقلق وصعوية التكيف مما يدفعهم إلى الإنجذاب للإنترنت والتعلق بمواقع محددة قد لا تدفع باتجاه الإنجذاب الإجتماعي فيولد صراعا وفراغا ذاتيا لديهم.

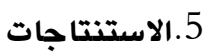

توصل الباحثان في البحث الحالي الى التائج الاتية: 1. وجود حالة الشعور بالاغتراب النفسي لدى فئة قليلة من افراد عينة البحث 2. عدم وجود فروق بين افراد عينة البحث ومتغيرات البحث في (الجنس،المرحلة الدراسية، القسم الداخلي )من حيث الشعور

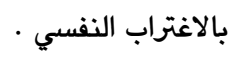
3. .وجود شعور اعلى لدى الذين يسكنون القسم الداخلي 4. ان اغلبية افراد عينة البحث يستخدمون الانترنت وكان هناك علاقة لدئ طردية بين استخدام الانترنت بما يتاح من الاجهزة وفترات اعلى من ثلاث ساعات في اليوم الواحد والذي يستخدمون الانترنت لغير العلاقات

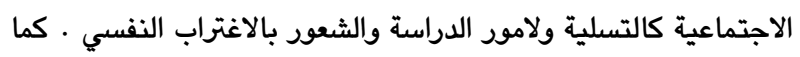
تبين ان نسبة ضئيلة منهم شعروا بالتحسن في مدى تقبلهم من قبل ولاجل اسرهم واصدقائهم واقربائهم .في حين ان نسبة اعلى منهم شعروا 
22. صالح ،يوسف حمه(2008) بحوث معاصرة في علم النفس ،ط1 ،دار الدجلة للنشر والتوزيع ،الاردن -عمان. 23. عباس،فيصل(2008) الاغتراب (الانسان المعاصر وشقاء الوعي)،دار المنهل اللبناني للطبع و النشر و التوزيع،لبنان - بيروت.

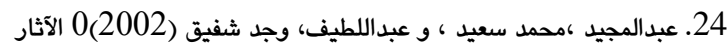
الإجتماعية للإنترنت على

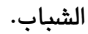

.http://www.alsdaqa.com/vb/showthread.php?t=166 25. عبد الحي،فخر عدنان(2008) الاغتراب النفسي لدى المسنين الذين يعملون في أعمال خاصة.WWW.nesasy.org. 26. عثمان،اسيا الصادق محمد ، و معاذ ،اسيا جبريل (2012) الاغتراب النفسي

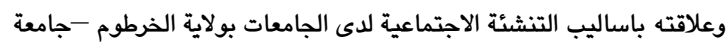
السودان للعلوم و التكنولوجيا - رسالة ماجستير منشورة.

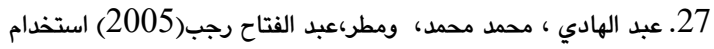

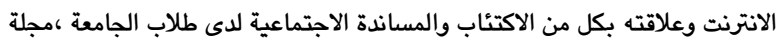
كلية التربية ببني سويف- جامعة القاهرة - العدد(4).

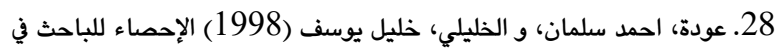
التربية والعلوم الإنسانية ، دار الفكر للنشر و التوزيع ، عمان - الأردن.

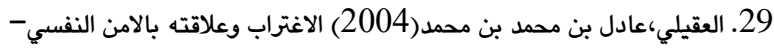
دراسة ميدانية على عينة من طلاب جامعة الامام محمد بن سعود الاسلامية بمدينة رياض الرياض .رسالة ماجستير منشورة. 30. فيركسون ،جورج اي (1991)، التحليل الإحصائي في التربية و علم النفس، منسورة

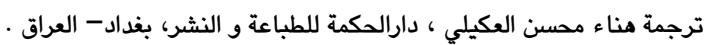

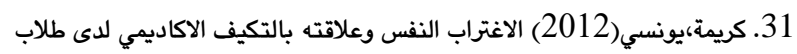

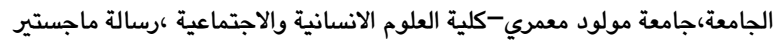
منشورة.

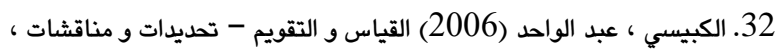

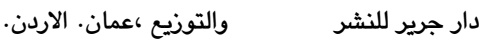

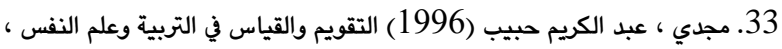
الطبعة الأولى ، مكتبة النهضة المصرية للطباعة و النشر ، القاهرة - مصر.

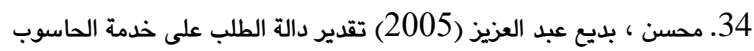

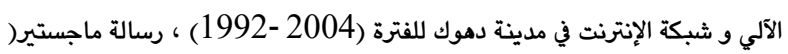

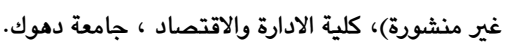

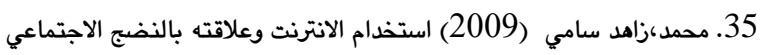
لدى المراهقين في اقليم كوردستان،جامعة دهوك-كلية التربية - رسالة ماجستير

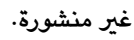
36. مسن،بول، و كنجر، جون، و كاجان، جيروم (1986) أسس سيكولوجية الطفولة والمرامقة، ط1، مكتبة الفلاح، الكويت.

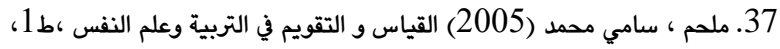
دار المسيرة للنشر و التوزيع و الطباعة ، عمان الاردن.

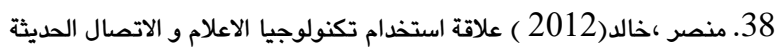
باغتراب الشباب الجامعي.جامعة الحاج لخضر - باتنة - قسم العلوم الانسانية رسالة ماجستر منشورة . 39. نصر الله ، عمر عبد الرحيم (2001) · مبادئ الاتصال التربوي ، دار وائل للنشر والتوزيع ،عمان - الأردن.

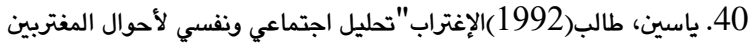
وأوضاعهم، ط1، المكتبة الوطنية، عمان، الأردن.
2. أبو جادو، صالح محمد علي(2007) علم النفس التطوري"الطفولة المراهقة"، ط2، دار المسيرة للنشر، عمان، الأردن.

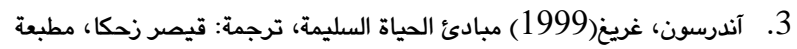
اليازجي، دمشق، سوريا. 4. الاسطل،يعقوب يونس خليل (2011) مشكلات النفس اجتماعية والانحرافات السلوكية لدى المترددي على مراكز الانترنت بمحافظة خان يونس .كلية التربية الجامعة الاسلامية - غزة -رسالة ماجستير منشورة . 5. بكر، أحمد الياس (1979). قياس مفهوم الذات والاغتراب لدى طلبة الجامعة. رسالة دكتوراه،

كلية الأداب الجامعة المستنصرية. 6. بدير،محمد نبيه (2005)الشعور بالاغتراب وعلاقته بالتوافق النفسى لدى الدئي المعلمين التربويين وغير التربويين، جامعة المنصورة - كلية التربية - المجلة العلمية، المجلد 14 العدد 2 الصفحات 123 : 179 7. جورارد،سيدني م ، ولندزمن، تيد(1988) الشخصية السليمة. ترجمة حمد ل دلي الكربولي وموفق الحمداني ، بغداد ،مطبعة التعليم العالي.

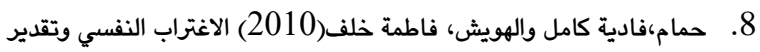
الذات لدى خريجات الجامعة العاملات والعاطلات عن العمل ـمجلة جامعة ام القرى

ل العلوم التربوية و النفسية. 9. الدديدي، فايز (1990). مظاهر الأغتراب وعوامله لدى طلبة الجامعة الأردنية. رسالة دكتوراه، جامعة عين شمس-القاهرة. 10. الحلبي ، موفق هاشم (2000).الأضطرابات النفسية عند الأطفال والمراهقين

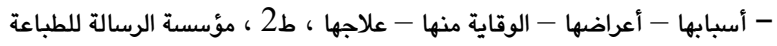
والنشر والتوزيع ، بيوت - لبنان.

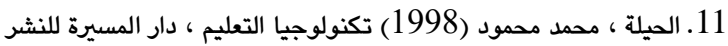
والتوزيع والطباعة ،عمان الأردن 12. خليفة ،عبد اللطيف محمد (2003) سيكولوجية الاغتراب النفسي ،دار غريب الإنب للطباعة و النشر و التوزيع - القاهرة - مصر.

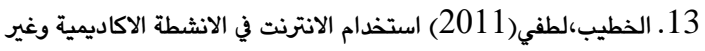

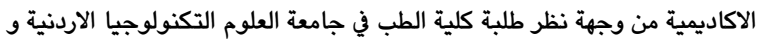

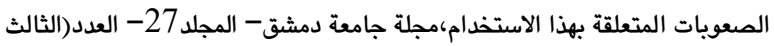
والرابع). 14. دسوقي، كمال( 1979)النمو التربوي للطفل والمراهق" دروس في علم النفس الإرتقائي"، ط1 ، ، دار النهضة العربية، بيروت.

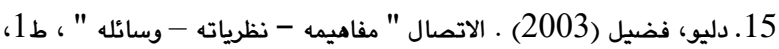
دار الفجر للنشر والتوزيع ، القاهرة. 16. رجب، محمود(1978)الأغتراب. منشأة المعارف المصرية للنشر -القاهرة.

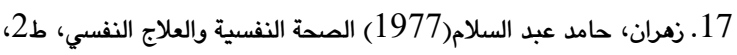
مطبة دار العالم العربي، القاهرة. 18. زهران ،سناء حامد (2004) ارشاد الصحة النفسية لتصحيح مشاعر العرات

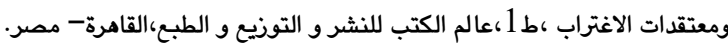

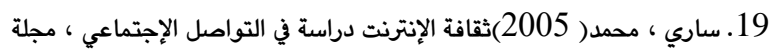

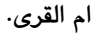
20. الساعدي ،ابراهيم (2007) العلاقة بين الاغتراب والتوافق النفسي للجالية العراقية في السويد - اطروحة دكتوراه منشورة ،اسم الموقع .www.ejtemay.com 21. شحادة،اسماء محمد(2012) الاغتراب النفسي وعلاقته بالدافعية للانجاز لدى الدي المعاقين بصريا في محافظة غزة ،الجامعة الإسلامية غزة،كلية التربية ،رسالة ماجستير منشورة. 
الصورة النهائية للمقياس

يقوم الباحثان باجراء دراسة علمية ، وقد تم وضع عبارات تستهدف التعرف على موقفك منها من خلال اجابتك الصريحة والدقيقة التي نتوسمها فيك ،علما انه لا يوجد

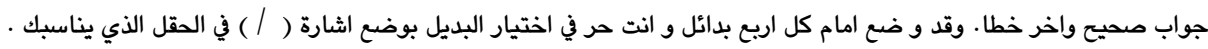
علما ان اجابتك هذه هي لأغراض البحث ولم يطلع احد عليها سوى الباحثان.

ملاحظة : أرجوا أن تملأ المعلومات أدناه قبل البدء بالإجابة على بنود الاستمارة.

\begin{tabular}{|c|c|c|c|c|c|}
\hline لا ينطبق & بدرجة علي & بندرجق & كبنطبق علي & 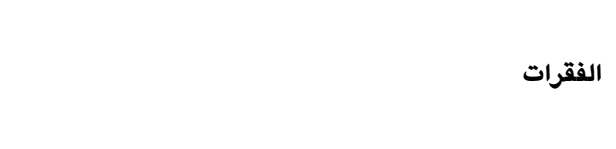 & ت \\
\hline & & & & ابتعد عن تكوين صداقات مع الاخرين . & 1 \\
\hline & & & & اشعر بالوحدة حتى عندما اكون بين افراد اسرتي. & 2 \\
\hline & & & & اشعر انني غربت عن زملائي. & 3 \\
\hline & & & & اشعر بالسعادة حينما اكون وحيدا. & 4 \\
\hline & & & & يصفني الاخرون باني بارد المشاعر. & 5 \\
\hline & & & & لا اطلع احدا على امور حياتي الخاصة. & 6 \\
\hline & & & & اشعر بضعف القدرة على القيام باي عمل . & 7 \\
\hline & & & & تفوتني الفرص غالبا في حسم الامور. & 8 \\
\hline & & & & اجد صعوبة في اقناع الاخرين بوجهة نظري . & 9 \\
\hline & & & & اشعر بان وجودي غير مهم. & 10 \\
\hline & & & & اتهرب من المواقف التي يتطلب تحمل المسؤولية. & 11 \\
\hline & & & & اجد صعوبة على ان اتمسك بحقوقي. & 12 \\
\hline & & & & تضايقني القيم الاجتماعية التي تحول بيني و بين تحقيق اهدافي . & 13 \\
\hline & & & & تمسكي بالقيم تعتمد على المواقف والأشخاص. & 14 \\
\hline & & & & استخدم كافة الوسائل المتاحة لبلوغ اهدافي. & 15 \\
\hline & & & & يحق لي ان افعل ما اريد في الحياة. & 16 \\
\hline & & & & من معاشرتي للناس تبين انه لا داعي للتمسك بالقيم. & 17 \\
\hline & & & & الدظ تدير حياتي اكثر من قدراتي. & 18 \\
\hline & & & & اعيش دون التخطيط لمستقبلي. & 19 \\
\hline & & & & ان نجحت او فشلت فالأمر عندي سواء. & 20 \\
\hline
\end{tabular}




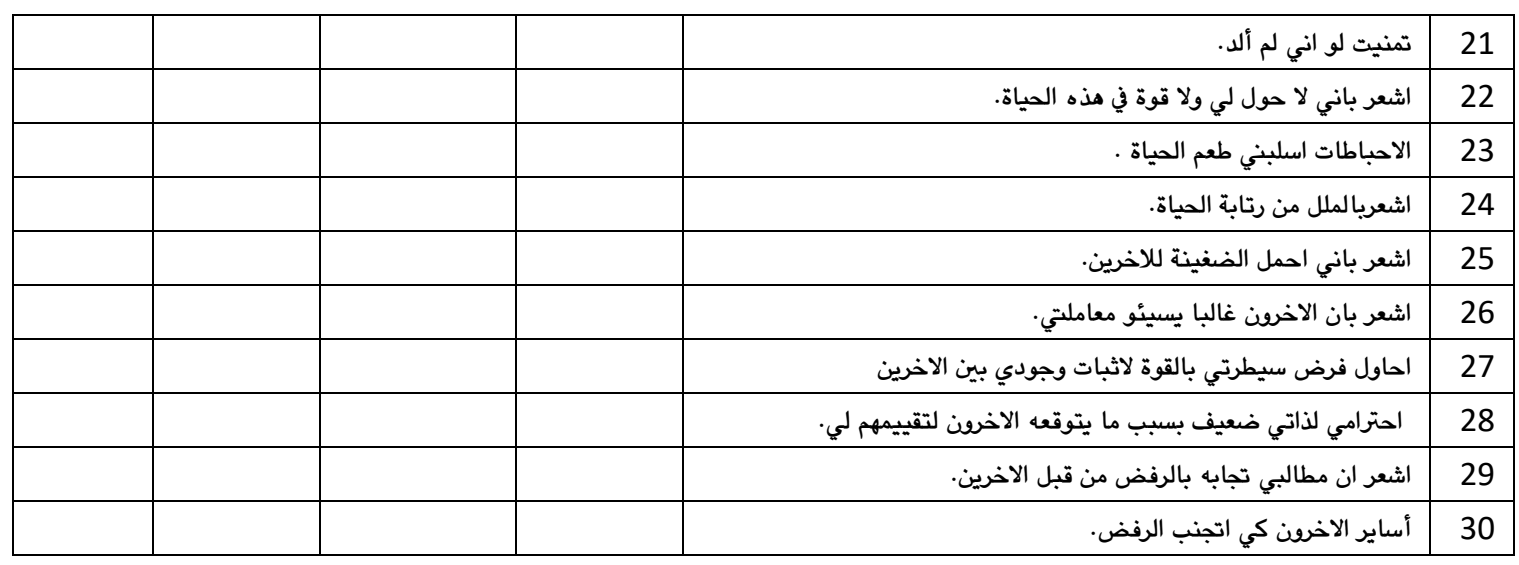

ملحق استبانة استخدام الإنترنت :

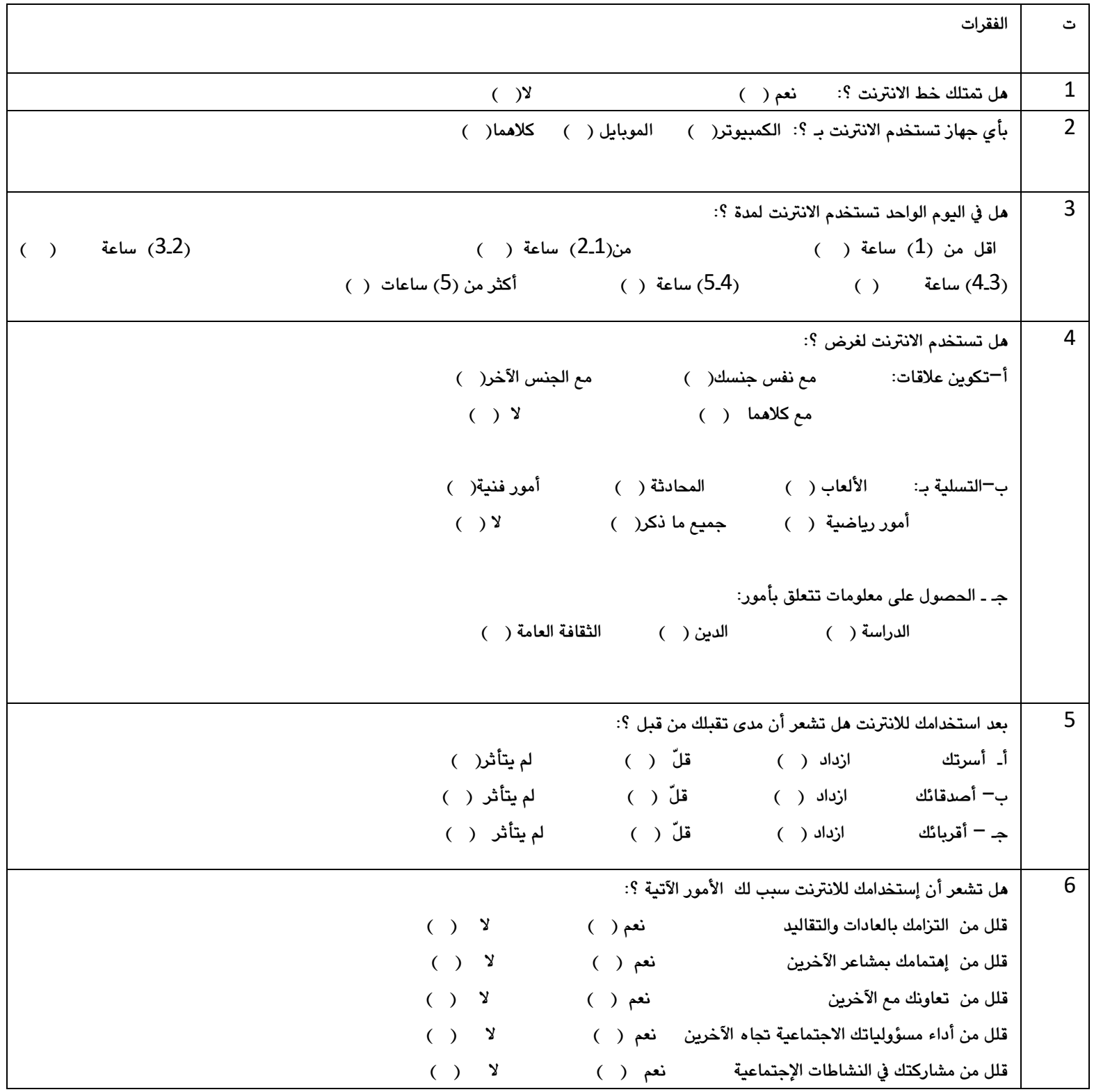




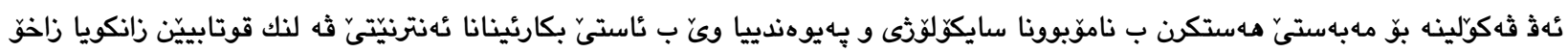

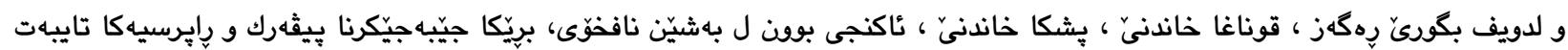

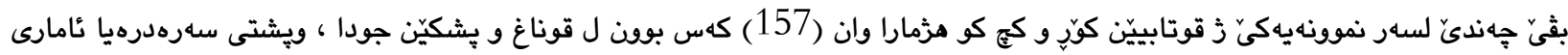

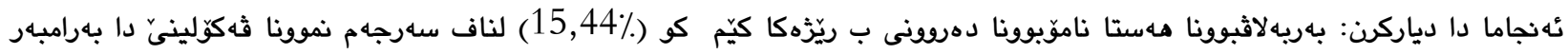

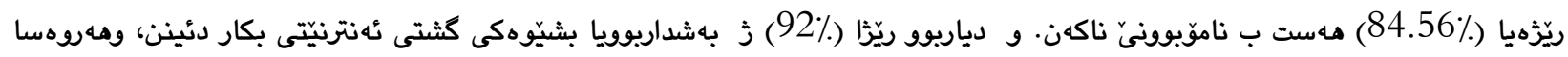

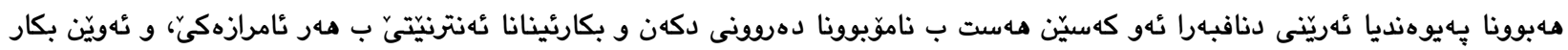

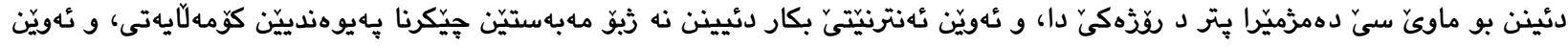

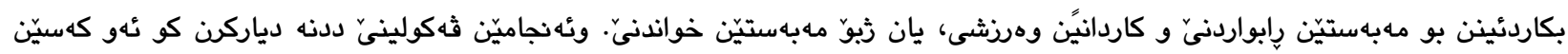

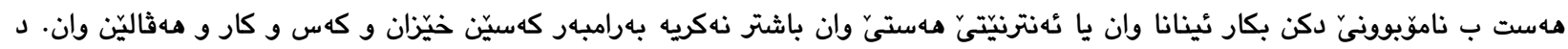

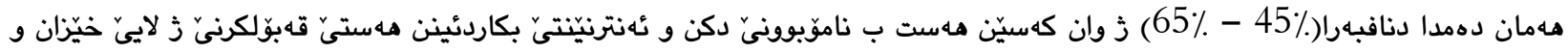

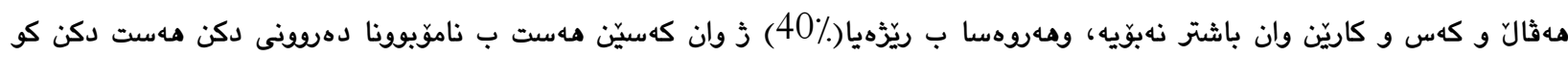

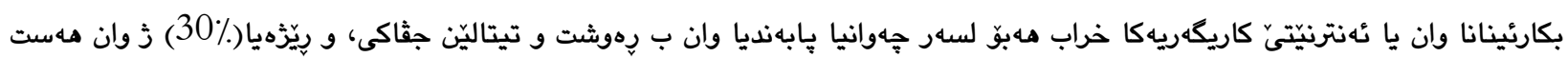

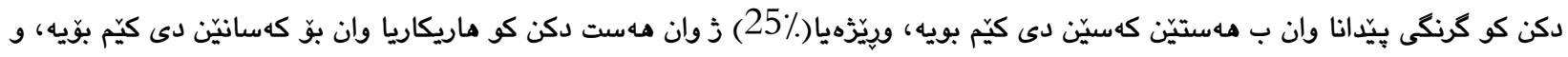

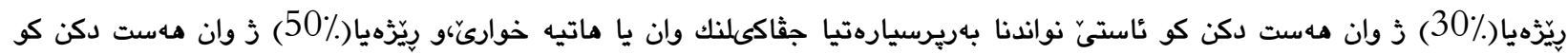

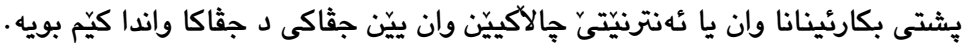

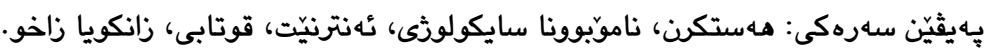

\title{
Feeling Psychological Alienation and its relation with Internet using among Zakho university students.
}

\begin{abstract}
:
The study aimed to introduce feeling psychological alienation and internet using among Zakho university students, according to gender, classes ‘ department ‘ by applied scale of psychological alienation feeling and practicing related questionnaires on a sample of) 157) students from different classes and department، after using relevant statistical formula, and gained that there is a feeling psychological alienation almost $(15.44 \%$ ), while) $84.56 \%$ ) of them don't feel it. The result showed that almost $(\% 92)$ from the over-all member of sample using internet, also showed that there is a parallel relationship between those who use internet by any tools, who using for more than three hours per a day and those who use it for non-public social relations, those who use it for entertainment, athletic, scientific purposes and its psychological alienation feeling. Results, also showed that using internet doesn't causes to improvement psychological alienation toward members of family, friends and folk. From other side $(45 \%-65 \%)$ of those who feel psychological alienation by using internet don't feel improvement in the level of family, friends and folk's acceptance. While nearly $(40 \%)$ of those who feel psychological alienation believed that using internet by them effected on their abiding by social rules, as well as about(30\%) of them feel that caring about others emotions decreased. Furthermore nearly $(25 \%)$ of them feel that level of cooperating with others has been decreased. In addition to about (30\%) feel that their social responsibility towards other have been decreased . Besides about) 50 (\%them feel that after using internet their social activities have been decreased in the society.
\end{abstract}

Keywords: Feelings, Psychological Alienation, Internet, Students, University of Zakho. 